\title{
INITIATION OF COMBUSTION BY LASER-INDUCED EXCITATION OF MOLECULAR VIBRATIONS OF REACTANTS*
}

\author{
A. M. Starik, B. I. Lukhovitsky, and N. S. Titova \\ Central Institute of Aviation Motors \\ Aviamotornaya Street 2, Moscow 111116, Russia \\ e-mail: star@ciam.ru
}

\begin{abstract}
The features of combustion initiation in $\mathrm{H}_{2}$ /air and $\mathrm{CH}_{4}\left(\mathrm{C}_{2} \mathrm{H}_{2}\right)$ /air mixtures under laser-induced excitation of the asymmetric mode of ozone molecules added in a small amount to the mixture are analyzed. It was shown that such an approach to supply radiation energy to the combustible mixtures reduces the induction time and decreases the ignition temperature at a small energy of laser radiation delivered to the mixture. These effects are explained mostly by two factors - the intensification of chain reactions due to acceleration of O-atom formation during dissociation of vibrationally excited $\mathrm{O}_{3}$ molecules and the heating of the mixture due to a faster decomposition of $\mathrm{O}_{3}$ molecules. The considered method of ignition/combustion control is much more effective (by a factor of 10-100) than the method based on heating the gas by resonance laser radiation in the case where the characteristic time of highly reactive radical and atom formation does not exceed significantly the relaxation time of the asymmetric mode of the $\mathrm{O}_{3}$ molecule.
\end{abstract}

Keywords: vibration excitation, combustion enhancement, chain reactions.

\section{Introduction}

Chemical reactions are at the basis of a number of technological processes, including combustion. Finding ways to intensify chemical processes is an important goal of chemical physics and combustion science. An effective method for accelerating chemical reactions is excitation of vibrational or electronic degrees of freedom of reactive molecules. Experimental data show that molecules excited even to the lowest vibrational or electronic states react 10-100 times faster than unexcited ones [1-4]. The burning of the most combustible mixtures occurs through the mechanism of chain-branching reactions. Therefore, in order to enhance the combustion, one needs to excite those molecules that can produce in the course of chemical reactions the highly reactive atoms and radicals. One efficient approach to exciting the vibrational or electronic states of target molecules is exposure of the mixture to resonance laser radiation.

It is worth noting that the use of laser radiation for affecting combustion has been widely discussed during the past decades [5-9]. Until now, only three methods of laser-assisted combustion initiation, such as laser-induced thermal ignition, laser-induced photochemical ignition, and laser-induced spark ignition, have been realized in experiments. All the methods have a number of limitations and their efficiency is rather small. There is a principal difference between the existing means of laser-induced initiation of

* Based on a talk presented at the Second International Symposium on Nonequilibrium Processes, Combustion, and Atmospheric Phenomena (Dagomys, Sochi, Russia, October 3-7, 2005).

Manuscript submitted by the authors in English on March 15, 2006.

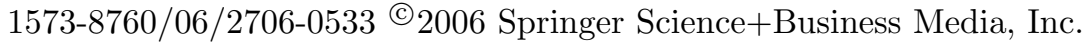


combustion and that considered in this paper. In the latter approach, highly reactive radicals and atoms participating in the chain process originate in the course of chemical reactions involving vibrationally or electronically excited molecules.

Recent studies have demonstrated that laser-induced excitation of oxygen molecules to the $a^{1} \Delta_{g}$ and $b^{1} \sum_{g}^{+}$electronic states leads to reduction of the ignition threshold and to a significant decrease in induction and combustion zone lengths in a supersonic flow of $\mathrm{H}_{2} / \mathrm{O}_{2}$ and $\mathrm{CH}_{4} / \mathrm{O}_{2}$ mixtures behind an inclined shock wave $[10,11]$. The excitation of $\mathrm{O}_{2}$ molecules to the singlet electronic states $a^{1} \Delta_{g}$ and $b^{1} \sum_{g}^{+}$may be attained by using laser radiation of near infrared (IR), at wavelength $\lambda_{I}=1.268 \mu \mathrm{m}$, or visible, at $762 \mathrm{~nm}$ wavelength, ranges. At present, the radiation sources at these wavelengths are still expensive and cannot provide the required power. Therefore, it would be useful to find a way of combustion control by means of laser-induced excitation of reacting molecules at wavelengths that are

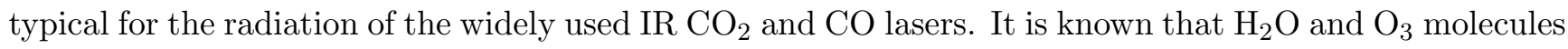
strongly absorb $\mathrm{CO}_{2}$ laser radiation at vibrational-rotational transitions. The present work is focused on the analysis of the possibility of combustion control by laser-induced excitation of vibrations of $\mathrm{O}_{3}$ molecules admixed in a small amount to $\mathrm{H}_{2}$ /air or $\mathrm{C}_{n} \mathrm{H}_{m}$ /air combustible mixtures.

\section{Methodology and Kinetic Model}

The ozone molecule is nonlinear and has normal vibrations of three types - symmetric, bending, and asymmetric modes. The frequencies of these vibration types are $\nu_{1}=1103.15 \mathrm{~cm}^{-1}, \lambda_{2}=700.95 \mathrm{~cm}^{-1}$, and $\lambda_{3}=1042 \mathrm{~cm}^{-1}$. The rotational structure of the $\mathrm{O}_{3}$ molecule is represented by asymmetric top quantum levels. The system of rotational levels of the asymmetric top is characterized by three quantum numbers $-J, K_{a}$, and $K_{c}$. The first number defines the total angular momentum of the asymmetric top, and the two latter ones $\left(K_{a}\right.$ and $\left.K_{c}\right)$ determine the projections of the total angular momentum onto oblate and prolate symmetric top axes. Ozone molecules absorb the radiation of a conventional $\mathrm{CO}_{2}$ laser in the wavelength range $\lambda_{I}=9.6-9.8 \mu \mathrm{m}[12,13]$. A minor shift between the $\mathrm{CO}_{2}$-laser-generated radiation with $\lambda_{I}=9.713998 \mu \mathrm{m}$, which corresponds to the $\mathrm{P} 38\left(00^{\circ} 1-02^{\circ} 0\right)$ line, and the wavelength at the center line of the absorbing transition in the ozone molecule appears for the vibrational-rotational transition $000\left(12_{1,11}\right) \rightarrow 001\left(11_{1,10}\right)$ (the wavelength at the center of the spectral line $\lambda_{m n}$ is $\left.9.714085 \mu \mathrm{m}\right)$. The Einstein coefficient for this transition is as large as $10.65 \mathrm{~s}^{-1}$.

The absorption of $\mathrm{CO}_{2}$ laser photons at $\lambda_{I} \approx 9.7 \mu \mathrm{m}$ by $\mathrm{O}_{3}$ molecule leads to excitation of the $\nu_{3}$ mode. The rate of induced transition resulting in excitation of the 001 state of the $\mathrm{O}_{3}$ molecule $W_{I}$ is governed by the following expression:

$$
W_{I}=\frac{\sigma_{m n} I}{h \nu_{I}}, \quad \sigma_{m n}=\frac{\lambda_{m n}^{2}}{4 \pi b_{D}} \sqrt{\frac{\ln 2}{\pi}} A_{m n} H(\tilde{x}, a), \quad \tilde{x}=\frac{2\left(\nu_{I}-\nu_{m n}\right)}{b_{D}} \sqrt{\ln 2}, \quad a=\frac{b_{c} \sqrt{\ln 2}}{b_{D}},
$$

where $I$ is the laser-radiation intensity, $\nu_{I}$ is the laser-radiation frequency, $h$ is Planck's constant, $\lambda_{m n}$ and $\nu_{m n}$ are the wavelength and frequency at the center of the spectral line due to absorbing transition $m \rightarrow n, A_{m n}$ is the Einstein coefficient for this transition, $b_{D}$ and $b_{c}$ are the Doppler and collisional widths of the line at its half height, and $H(\tilde{x}, a)$ is the Voight function.

The subject of our modeling is the laser-induced ignition of quiescent stoihiometric $\mathrm{H}_{2} /$ air $/ \mathrm{O}_{3}$ and $\mathrm{CH}_{4}\left(\mathrm{C}_{2} \mathrm{H}_{2}\right) /$ air $/ \mathrm{O}_{3}$ mixtures. Consider the case where $\tau_{I}>\tau_{t}, \tau_{r}, \tau_{V V}$, with $\tau_{t}$ and $\tau_{r}$ being the characteristic times of the translational and rotational relaxation, $\tau_{V V}$ the characteristic time of intramode 
vibrational-vibrational (VV) exchange, and $\tau_{I}=W_{I}^{-1}$ the time of induced transition. Under this condition, it can be assumed that the translational and rotational degrees of freedom of molecules are in thermodynamic equilibrium. A local Boltzmann distribution is assumed to hold within each vibrational mode with its own vibrational temperature $T_{\xi}(\xi=1, \ldots, n$, where $n$ is the number of vibrational modes of the molecular components formed by combustion reactions). In order to provide a relatively large concentration of excited molecules, the condition $\tau_{I}<\tau_{R}^{V}$ should be met, where $\tau_{R}^{V}$ is the relaxation time of the vibrational energy of excited molecules.

It is known that in order to describe the ignition/combustion of $\mathrm{H}_{2}$ /air and $\mathrm{CH}_{4}\left(\mathrm{C}_{2} \mathrm{H}_{2}\right)$ /air mixtures, a rather complicated reaction mechanism must be used even in the absence of vibrationally excited molecules [14-18]. A number of different chemical kinetic models have been proposed to simulate the ignition/combustion in methane (or acetylene)/oxygen mixtures under thermal-equilibrium conditions, where the vibrational degrees of freedom of molecules are in thermodynamic equilibrium with translational and rotational ones. However, most of them are not involved in the reactions with $\mathrm{O}_{3}$ molecules. To describe the ignition/combustion in $\mathrm{CH}_{4}\left(\mathrm{C}_{2} \mathrm{H}_{6}\right)$ /air mixtures involving such reactions, a kinetic model was developed by Dautov and Starik [16]. This model has been supplemented by reactions involving $\mathrm{C}_{3} \mathrm{H}_{3}, \mathrm{C}_{2} \mathrm{H}_{3}, \mathrm{C}_{2} \mathrm{H}, \mathrm{CH}_{2}\left(\tilde{a}^{1} A_{1}\right)$ species which usually originate during the ignition of acetylene/oxygen mixtures $[17,18]$. The extended model includes 311 reversible reactions with the following species:

$\mathrm{H}_{n}(n=1,2), \mathrm{O}_{m}(m=1 \ldots 3), \mathrm{HO}_{n}, \mathrm{H}_{2} \mathrm{O}_{n}, \mathrm{~N}_{n}, \mathrm{NO}_{n}, \mathrm{C}, \mathrm{CO}_{n}$,

$\mathrm{CH}_{p}(p=1 \ldots 4), \mathrm{C}_{2} \mathrm{H}_{q}(q=1 \ldots 6), \mathrm{CH}_{2}\left(\tilde{a}^{1} A_{1}\right), \mathrm{C}_{3} \mathrm{H}_{m+1}, \mathrm{C}_{4} \mathrm{H}_{m+1}, \mathrm{CH}_{m} \mathrm{O}$,

$\mathrm{CH}_{3} \mathrm{O}_{2}, \mathrm{CH}_{3} \mathrm{O}_{2} \mathrm{H}, \mathrm{CH}_{n+1} \mathrm{OH}, \mathrm{C}_{2} \mathrm{HO}, \mathrm{CH}_{2} \mathrm{CO}$,

and allows one to obtain a good agreement between computed and measured ignition delay times for $\mathrm{H}_{2} / \mathrm{O}_{2}$ (air), $\mathrm{CH}_{4} / \mathrm{O}_{2}$, and $\mathrm{C}_{2} \mathrm{H}_{2} / \mathrm{O}_{2}$ stoichiometric mixtures in a wide domain of initial temperatures and pressures.

For thermally nonequilibrium conditions, where the distribution of vibrational energy in reactive molecules is specified by vibrational temperatures $T_{\xi}$, the set of chemical reactions should be supplemented by the channels of vibrational-energy intermode ( $\mathrm{VV}^{\prime}$ ) exchange and the pathways of vibrationaltranslational (VT) relaxation. Within the framework of the mode-resolved model adopted in the present work, we considered the $\mathrm{VV}^{\prime}$ exchange between the symmetric, deformation, and asymmetric $\left(\nu_{1}, \nu_{2}\right.$, and $\left.\nu_{3}\right)$ modes of $\mathrm{H}_{2} \mathrm{O}$ molecules, the modes of molecules of $\mathrm{H}_{2}\left(\nu_{4}\right), \mathrm{O}_{2}\left(\nu_{5}\right), \mathrm{OH}\left(\nu_{6}\right), \mathrm{N}_{2}\left(\nu_{7}\right), \mathrm{NO}\left(\nu_{8}\right)$, and $\mathrm{CO}\left(\nu_{21}\right)$, the symmetric, deformation, and asymmetric modes of molecules of $\mathrm{NO}_{2}\left(\nu_{9}, \nu_{10}, \nu_{11}\right)$, $\mathrm{HO}_{2}\left(\nu_{12}, \nu_{13}, \nu_{14}\right), \mathrm{O}_{3}\left(\nu_{15}, \nu_{16}, \nu_{17}\right)$, and $\mathrm{CO}_{2}\left(\nu_{18}, \nu_{19}, \nu_{20}\right)$, and the VT relaxation processes for the modes $\nu_{2}, \nu_{4}, \nu_{5}, \nu_{6}, \nu_{7}, \nu_{8}, \nu_{10}, \nu_{14}, \nu_{16}, \nu_{19}$, and $\nu_{21}$. It is known that vibrational relaxation in hydrocarbon molecules proceeds much faster than the relaxation in diatomic and triatomic molecules [19]. According to these data, the vibrations of hydrocarbon molecules were assumed to be in thermodynamic equilibrium with translational degrees of freedom.

Table 1 presents the $\mathrm{VV}^{\prime}$ and VT exchange channels involved in the model. The temperature dependences of rate coefficients for intermode $\mathrm{VV}^{\prime}$ processes Nos. 5-10, 14-19, 22-24, 31-34, and 38 as well as the rate coefficients for processes Nos. 1-4, 11-13, 20-21, 25-30, and 35-37 for $\mathrm{M}=\mathrm{H}_{2} \mathrm{O}, \mathrm{H}_{2}, \mathrm{O}_{2}, \mathrm{O}_{3}$, $\mathrm{H}, \mathrm{O}, \mathrm{OH}, \mathrm{HO}_{2}, \mathrm{H}_{2} \mathrm{O}_{2}, \mathrm{NO}, \mathrm{NO}_{2}, \mathrm{~N}_{2}$, and $\mathrm{N}$ were taken from [20], and for $\mathrm{M}=\mathrm{C}_{n} \mathrm{H}_{m} \mathrm{O}_{l}$ and $\mathrm{C}_{n} \mathrm{H}_{m}$ were estimated using the formula

$$
W_{\xi, p}^{M}=W_{\xi, p}^{M^{*}} \frac{Q_{\xi, p}^{M}}{Q_{\xi, p}^{M^{*}}},
$$

where $Q_{\xi, p}^{M^{*}}$ is the rate coefficient calculated using the Millikan-White formula [21] at $\mathrm{M}^{*}=\mathrm{N}, \mathrm{NO}, \mathrm{NO}_{2}$, 
and $\mathrm{OH}$ for $\mathrm{M}=\mathrm{C}, \mathrm{CO}, \mathrm{CO}_{2}$, and $\mathrm{CH}$, respectively, and $\mathrm{M}^{*}=\mathrm{H}_{2} \mathrm{O}$ for other mixture components. The rate coefficients for reactions Nos. $40-43$ for $\mathrm{M}=\mathrm{CO}_{2}, \mathrm{CO}, \mathrm{N}_{2}, \mathrm{NO}, \mathrm{H}_{2} \mathrm{O}, \mathrm{H}_{2}, \mathrm{OH}, \mathrm{O}_{2}, \mathrm{O}$, and $\mathrm{H}$ were reported in [22], and for other $M$ 's the rate coefficients were calculated using formula (1), where $W_{\xi, p}^{M^{*}}$ and $Q_{\xi, p}^{M^{*}}$ at $\mathrm{M}^{*}=\mathrm{O}, \mathrm{N}_{2} \mathrm{O}$, and $\mathrm{OH}$ were used to calculate $W_{\xi, p}^{M}$ and $Q_{\xi, p}^{M}$ for $\mathrm{M}=\mathrm{N}, \mathrm{NO}_{2}$, and $\mathrm{CH}$, respectively, and the $W_{\xi, p}^{M^{*}}$, and $Q_{\xi, p}^{M^{*}}$ with $\mathrm{M}^{*}=\mathrm{H}_{2} \mathrm{O}$ were taken to calculate the corresponding magnitudes for $\mathrm{M}=$ $\mathrm{HO}_{2}, \mathrm{H}_{2} \mathrm{O}_{2}, \mathrm{O}_{3}, \mathrm{C}_{n} \mathrm{H}_{m} \mathrm{O}_{l}$, and $\mathrm{C}_{n} \mathrm{H}_{m}$. The rate coefficients for the reactions Nos. 39, 44-49 were taken from [22].

Within the model of mode vibrational kinetics, the rate constant for the $r$ th chemical reaction is a function of translational (gas) $T$ and vibrational $T_{\xi}$ temperatures

$$
k_{r}=k_{r}^{0}(T) \varphi\left(T_{\xi}, T\right)
$$

where $k_{r}^{0}(T)$ is the equilibrium rate constant for the $r$ th chemical reaction and $\varphi\left(T_{\xi}, T\right)$ is the nonequilibrium factor calculated similar to [20]. The dependences for $k_{r}^{0}(T)$ were selected based on the recommendations of $[16-18,20]$.

\section{Formulation of the Problem and Governing Equations}

Consider a stationary homogeneous $\mathrm{H}_{2}$ /air or $\mathrm{CH}_{4}\left(\mathrm{C}_{2} \mathrm{H}_{2}\right)$ /air mixtures containing a small amount of $\mathrm{O}_{3}$ molecules, which are exposed to a laser radiation pulse of duration $\tau_{p}$ at wavelength $\lambda_{I}=9.713998 \mu \mathrm{m}$. Let us analyze the processes in the central zone of the laser beam $\left(r<R_{a}\right)$ with a Gaussian intensity distribution along the radius

$$
I(r, t)=I_{0}(t) e^{-r^{2} / R_{a}^{2}},
$$

where $R_{a}$ is the characteristic beam radius, and $I_{0}(t)=I_{0}$ for $0<t \leq \tau_{p}$ and $I_{0}(t)=0$ for $t>\tau_{p}$.

For processes in the laser-radiation field, an important quantity is the absorption coefficient $k_{\nu}$, which is related to the absorption cross section $\sigma_{m n}$ as follows:

$$
k_{\nu}=\sigma_{m n}\left(\frac{g_{n}}{g_{m}} N_{m}-N_{n}\right)
$$

where $g_{m}$ and $g_{n}$ are the degeneracy multiplicity of the lower $(m)$ and upper $(n)$ states of the absorption transition, and $N_{m}$ and $N_{n}$ are the densities of $\mathrm{O}_{3}$ molecules in these states. For the $000 \rightarrow 001$ vibrational transition,

$$
\begin{gathered}
N_{m}=N_{\mathrm{O}_{3}} \frac{g_{m}}{z_{m}} \exp \left(-\frac{E_{J^{\prime}}}{K T}\right), \quad N_{n}=N_{\mathrm{O}_{3}} \frac{g_{n}}{z_{n}} \exp \left(-\frac{E_{J^{\prime \prime}}}{K T}\right) y_{3}, \\
z_{q}(q=m, n)=\frac{1}{2} \sqrt{\frac{\pi T^{3}}{A_{q} B_{q} C_{q}}} \prod_{\xi=1}^{3}\left(1-y_{\xi 0}\right)^{-1}, \quad y_{\xi}=e^{-\theta_{\xi} / T_{\xi}}, \quad y_{\xi 0}=y_{\xi}\left(T_{\xi}=T\right), \quad \theta_{\xi}=\frac{h \nu_{\xi}}{K},
\end{gathered}
$$

where $K$ is Boltzmann's constant, $N_{\mathrm{O}_{3}}$ is the concentration of $\mathrm{O}_{3}$ molecules in the mixture, $A_{q}, B_{q}$, and $C_{q}$ are the rotational constants of $\mathrm{O}_{3}$ molecule in the state $q$, and $E_{J^{\prime}}$ and $E_{J^{\prime \prime}}$ are the rotational energies of $\mathrm{O}_{3}$ molecule in the states $m$ and $n$, respectively.

Let $R_{a}$ be much smaller than the absorption length $L_{\nu}=k_{\nu}^{-1}$. Thus, we can ignore the variation in the parameters in the longitudinal direction compared to their variation across the beam and consider an optically thin gas layer. In this case, the variation in the hydrodynamic quantities and concentrations 
TABLE 1. Channels of VV' Exchange and VT Relaxation Involved in the Model.

\begin{tabular}{|c|c|c|}
\hline 1. & $\mathrm{H}_{2} \mathrm{O}(001)+M=\mathrm{H}_{2} \mathrm{O}(100)+M$ & $W_{3,1}^{M}$ \\
\hline 2. & $\mathrm{H}_{2} \mathrm{O}(001)+M=\mathrm{H}_{2} \mathrm{O}(020)+M$ & $W_{3,2}^{M}$ \\
\hline 3. & $\mathrm{H}_{2} \mathrm{O}(100)+M=\mathrm{H}_{2} \mathrm{O}(020)+M$ & $W_{1,2}^{M}$ \\
\hline 4. & $\mathrm{H}_{2} \mathrm{O}(010)+M=\mathrm{H}_{2} \mathrm{O}(000)+M$ & $W_{2,0}^{M}$ \\
\hline 5. & $\mathrm{H}_{2}(\mathrm{~V}=1)+\mathrm{H}_{2} \mathrm{O}(000)=\mathrm{H}_{2} \mathrm{O}(001)+\mathrm{H}_{2}(\mathrm{~V}=0)$ & $W_{4,3}$ \\
\hline 6. & $\mathrm{H}_{2}(\mathrm{~V}=1)+\mathrm{H}_{2} \mathrm{O}(000)=\mathrm{H}_{2} \mathrm{O}(100)+\mathrm{H}_{2}(\mathrm{~V}=0)$ & $W_{4,1}$ \\
\hline 7. & $\mathrm{H}_{2} \mathrm{O}(010)+\mathrm{O}_{2}(\mathrm{~V}=0)=\mathrm{H}_{2} \mathrm{O}(000)+\mathrm{O}_{2}(\mathrm{~V}=1)$ & $W_{2,5}$ \\
\hline 8. & $\mathrm{H}_{2} \mathrm{O}(001)+\mathrm{OH}(\mathrm{V}=0)=\mathrm{H}_{2} \mathrm{O}(000)+\mathrm{OH}(\mathrm{V}=1)$ & $W_{3,6}$ \\
\hline 9. & $\mathrm{H}_{2} \mathrm{O}(100)+\mathrm{OH}(\mathrm{V}=0)=\mathrm{H}_{2} \mathrm{O}(000)+\mathrm{OH}(\mathrm{V}=1)$ & $W_{1,6}$ \\
\hline 10. & $\mathrm{H}_{2}(\mathrm{~V}=1)+\mathrm{OH}(\mathrm{V}=0)=\mathrm{H}_{2}(\mathrm{~V}=0)+\mathrm{OH}(\mathrm{V}=1)$ & $W_{4,6}$ \\
\hline 11. & $\mathrm{H}_{2}(\mathrm{~V}=1)+M=\mathrm{H}_{2}(\mathrm{~V}=0)+M$ & $W_{4,0}^{M}$ \\
\hline 12. & $\mathrm{O}_{2}(\mathrm{~V}=1)+M=\mathrm{O}_{2}(\mathrm{~V}=0)+M$ & $W_{5,0}^{M}$ \\
\hline 13. & $\mathrm{OH}(\mathrm{V}=1)+M=\mathrm{OH}(\mathrm{V}=0)+M$ & $W_{6,0}^{M}$ \\
\hline 14. & $\mathrm{~N}_{2}(\mathrm{~V}=1)+\mathrm{H}_{2} \mathrm{O}(000)=\mathrm{N}_{2}(\mathrm{~V}=0)+\mathrm{H}_{2} \mathrm{O}(010)$ & $W_{7,2}$ \\
\hline 15. & $\mathrm{OH}(\mathrm{V}=1)+\mathrm{N}_{2}(\mathrm{~V}=0)=\mathrm{OH}(\mathrm{V}=0)+\mathrm{N}_{2}(\mathrm{~V}=1)$ & $W_{6,7}$ \\
\hline 16. & $\mathrm{~N}_{2}(\mathrm{~V}=1)+\mathrm{O}_{2}(\mathrm{~V}=0)=\mathrm{N}_{2}(\mathrm{~V}=0)+\mathrm{O}_{2}(\mathrm{~V}=1)$ & $W_{7,5}$ \\
\hline 17. & $\mathrm{NO}(\mathrm{V}=1)+\mathrm{H}_{2} \mathrm{O}(000)=\mathrm{NO}(\mathrm{V}=0)+\mathrm{H}_{2} \mathrm{O}(010)$ & $W_{8,2}$ \\
\hline 18. & $\mathrm{NO}(\mathrm{V}=1)+\mathrm{O}_{2}(\mathrm{~V}=0)=\mathrm{NO}(\mathrm{V}=0)+\mathrm{O}_{2}(\mathrm{~V}=1)$ & $W_{8,5}$ \\
\hline 19. & $\mathrm{~N}_{2}(\mathrm{~V}=1)+\mathrm{NO}(\mathrm{V}=0)=\mathrm{N}_{2}(\mathrm{~V}=0)+\mathrm{NO}(\mathrm{V}=1)$ & $W_{7,8}$ \\
\hline 20. & $\mathrm{~N}_{2}(\mathrm{~V}=1)+M=\mathrm{N}_{2}(\mathrm{~V}=0)+M$ & $W_{7,0}^{M}$ \\
\hline 21. & $\mathrm{NO}(\mathrm{V}=0)+M=\mathrm{NO}(\mathrm{V}=0)+M$ & $W_{8,0}^{M}$ \\
\hline 22. & $\mathrm{O}_{2}(\mathrm{~V}=0)+\mathrm{NO}_{2}(001)=\mathrm{O}_{2}(\mathrm{~V}=1)+\mathrm{NO}_{2}(000)$ & $W_{11,5}$ \\
\hline 23. & $\mathrm{NO}_{2}(001)+\mathrm{H}_{2} \mathrm{O}(000)=\mathrm{NO}_{2}(000)+\mathrm{H}_{2} \mathrm{O}(010)$ & $W_{11,2}$ \\
\hline 24. & $\mathrm{NO}(\mathrm{V}=1)+\mathrm{NO}_{2}(000)=\mathrm{NO}(\mathrm{V}=0)+\mathrm{NO}_{2}(001)$ & $W_{8,11}$ \\
\hline 25 . & $\mathrm{NO}_{2}(020)+M=\mathrm{NO}_{2}(100)+M$ & $W_{10,9}^{M}$ \\
\hline 26. & $\mathrm{NO}_{2}(001)+M=\mathrm{NO}_{2}(020)+\mathrm{M}$ & $W_{11,10}^{M}$ \\
\hline 27. & $\mathrm{NO}_{2}(010)+M=\mathrm{NO}_{2}(000)+M$ & $W_{10,0}^{M}$ \\
\hline 28. & $\mathrm{HO}_{2}(100)+M=\mathrm{HO}_{2}(003)+M$ & $W_{12,14}^{M}$ \\
\hline 29. & $\mathrm{HO}_{2}(010)+M=\mathrm{HO}_{2}(001)+M$ & $W_{13,14}^{M}$ \\
\hline 30. & $\mathrm{HO}_{2}(001)+M=\mathrm{HO}_{2}(000)+M$ & $W_{14,0}^{M}$ \\
\hline 31. & $\mathrm{H}_{2} \mathrm{O}(100)+\mathrm{HO}_{2}(000)=\mathrm{H}_{2} \mathrm{O}(000)+\mathrm{HO}_{2}(100)$ & $W_{1,12}$ \\
\hline 32. & $\mathrm{O}_{2}(\mathrm{~V}=1)+\mathrm{HO}_{2}(000)=\mathrm{O}_{2}(\mathrm{~V}=0)+\mathrm{HO}_{2}(010)$ & $W_{5,13}$ \\
\hline 33. & $\mathrm{HO}_{2}(010)+\mathrm{NO}_{2}(000)=\mathrm{HO}_{2}(000)+\mathrm{NO}_{2}(100)$ & $W_{13,9}$ \\
\hline 34. & $\mathrm{H}_{2} \mathrm{O}(010)+\mathrm{HO}_{2}(000)=\mathrm{H}_{2} \mathrm{O}(000)+\mathrm{HO}_{2}(010)$ & $W_{2,13}$ \\
\hline 35. & $\mathrm{O}_{3}(001)+M=\mathrm{O}_{3}(100)+M$ & $W_{17,15}^{M}$ \\
\hline
\end{tabular}




\begin{tabular}{|c|c|c|}
\hline 36. & $\mathrm{O}_{3}(100)+M=\mathrm{O}_{3}(010)+M$ & $W_{15,16}^{M}$ \\
\hline 37. & $\mathrm{O}_{3}(010)+M=\mathrm{O}_{3}(000)+M$ & $W_{16,0}^{M}$ \\
\hline 38. & $\mathrm{~N}_{2}(\mathrm{~V}=1)+\mathrm{O}_{3}(000)=\mathrm{N}_{2}(\mathrm{~V}=0)+\mathrm{O}_{3}(101)$ & $W_{7, \Sigma}$ \\
\hline 39. & $\mathrm{CO}_{2}\left(00^{0} 1\right)+\mathrm{N}_{2}(\mathrm{~V}=0)=\mathrm{CO}_{2}\left(00^{0} 0\right)+\mathrm{N}_{2}(\mathrm{~V}=1)$ & $W_{20,7}$ \\
\hline 40 . & $\mathrm{CO}_{2}\left(00^{0} 1\right)+M=\mathrm{CO}_{2}\left(11^{1} 0,03^{1} 0\right)+M$ & $W_{20, \Sigma_{1}}^{M}$ \\
\hline 41. & $\mathrm{CO}_{2}\left(10^{0} 0\right)+M=\mathrm{CO}_{2}\left(02^{0} 0\right)+M$ & $W_{18,19}^{M}$ \\
\hline 42. & $\mathrm{CO}_{2}\left(01^{1} 0\right)+M=\mathrm{CO}_{2}\left(00^{0} 0\right)+M$ & $W_{19,0}^{M}$ \\
\hline 43. & $\mathrm{CO}(\mathrm{V}=1)+M=\mathrm{CO}(\mathrm{V}=0)+M$ & $W_{21,0}^{M}$ \\
\hline 44. & $\mathrm{CO}_{2}\left(00^{0} 1\right)+\mathrm{CO}(\mathrm{V}=0)=\mathrm{CO}_{2}\left(00^{0} 0\right)+\mathrm{CO}(\mathrm{V}=1)$ & $W_{20,21}$ \\
\hline 45. & $\mathrm{CO}_{2}\left(00^{0} 0\right)+\mathrm{CO}(\mathrm{V}=1)=\mathrm{CO}_{2}\left(11^{1} 0,03^{1} 0\right)+\mathrm{CO}(\mathrm{V}=0)$ & $W_{21, \Sigma_{1}}$ \\
\hline 46. & $\mathrm{CO}_{2}\left(00^{0} 0\right)+\mathrm{O}_{2}(\mathrm{~V}=1)=\mathrm{CO}_{2}\left(10^{0} 0\right)+\mathrm{O}_{2}(\mathrm{~V}=0)$ & $W_{5,18}$ \\
\hline 47. & $\mathrm{CO}(\mathrm{V}=1)+\mathrm{NO}(\mathrm{V}=0)=\mathrm{CO}(\mathrm{V}=0)+\mathrm{NO}(\mathrm{V}=1)$ & $W_{21,8}$ \\
\hline 48. & $\mathrm{CO}(\mathrm{V}=1)+\mathrm{O}_{2}(\mathrm{~V}=0)=\mathrm{CO}(\mathrm{V}=0)+\mathrm{O}_{2}(\mathrm{~V}=1)$ & $W_{21,5}$ \\
\hline 49. & $\mathrm{CO}(\mathrm{V}=1)+\mathrm{H}_{2} \mathrm{O}(000)=\mathrm{CO}(\mathrm{V}=0)+\mathrm{H}_{2} \mathrm{O}(010)$ & $W_{21,2}$ \\
\hline
\end{tabular}

of the components is determined by the hierarchy of the characteristic times of various macro- and micro-transfer processes [23,24].

For a vibrationally nonequilibrium reactive gas, the following are the times involved in the processes under consideration:

$\tau_{I}$ - time of induced transitions;

$\tau_{R}^{V}$ - time of energy relaxation of vibrationally excited states;

$\tau_{p}$ - radiation-pulse duration;

$\tau_{\mathrm{i}, \mathrm{r}}^{\mathrm{ch}}$ - time of the chemical reaction resulting in the formation of the component determining the igniting mechanism of the mixture;

$\tau_{a}$ - time of propagation of acoustic vibrations across the beam;

$\tau_{D, i}-$ time of multicomponent diffusion of the $i$ th component;

$\tau_{T, i}$ - time of thermal diffusion of the $i$ th component;

$\tau_{D, i}^{V}$ - time of vibrational thermal diffusion;

$\tau_{\lambda}$ - time of heat conduction;

$\tau_{V, j}$ - time of vibrational thermal conduction of the $j$ th oscillator;

$\tau_{c}$ - time of convection due to viscosity;

$\tau_{F}$ - time of state transition of the medium due to the striction force exerted.

For typical conditions of numerical experiments $\left(T_{0}=400-900 \mathrm{~K}, P_{0}=10^{3}-10^{5} \mathrm{~Pa}, I_{0}=1-\right.$ $20 \mathrm{~kW} / \mathrm{cm}^{2}$, and $\left.R_{a}=1 \mathrm{~cm}\right)$ for stoichiometric $\mathrm{H}_{2} /$ air and $\mathrm{CH}_{4}\left(\mathrm{C}_{2} \mathrm{H}_{2}\right) /$ air mixtures containing $0.5-5 \%$ ozone exposed to radiation at wavelength $\lambda_{I}=9.714 \mu \mathrm{m}$, the following estimates were obtained:

$\tau_{I}=7 \cdot 10^{-7}-6 \cdot 10^{-5} \mathrm{~s}, \quad \tau_{V T}=3 \cdot 10^{-3}-6 \cdot 10^{-4} \mathrm{~s}, \quad$ and $\quad \tau_{a}=2 \cdot 10^{-5} \mathrm{~s}$.

For the lightest $\mathrm{H}$ atoms, which are chain carriers in $\mathrm{H}_{2} / \mathrm{O}_{2} / \mathrm{N}_{2}$ mixtures,

$\tau_{D, \mathrm{H}} \approx \tau_{T, \mathrm{H}} \approx(0.2-5) \cdot 10^{-4} \mathrm{~s}, \tau_{D, \mathrm{O}_{3}}^{V}=(1-5) \cdot 10^{-3} \mathrm{~s}, \tau_{\lambda} \approx \tau_{V, \mathrm{O}_{3}}=(0.3-7.5) \cdot 10^{-4} \mathrm{~s}$, 
$\tau_{c} \sim \tau_{F}=10^{-2}-10^{-1} \mathrm{~s}$.

For the specified conditions, the absorption length of the laser radiation varies in the range $0.3-1.5 \cdot 10^{3} \mathrm{~m}$, i.e., always $L_{v} \gg R_{a}$.

We consider the cases where $\tau_{I} \leq \tau_{R}^{V} \approx \tau_{p} \approx \tau_{a}<\tau_{\mathrm{ch}}<\tau_{D, \mathrm{H}}, \quad \tau_{\lambda}, \quad \tau_{c}\left(\tau_{\mathrm{ch}}=\min \left[\tau_{\mathrm{i}, \mathrm{r}}^{\mathrm{ch}}\right]\right)$.

The time $\tau_{\mathrm{i}, \mathrm{r}}^{\text {ch }}$ determines the induction period $\tau_{\text {ind }}$. In the interval $\left[0, \tau_{\text {ind }}\right]$, macro-transfer processes can be ignored. In this case, the variation in the parameters and composition of the mixture in the central zone of the exposure region is described by the following equations:

$$
\begin{aligned}
& \frac{d \gamma_{i}}{d t}=G_{i}-\gamma_{i} \sum_{k=1}^{M_{1}} G_{k} \\
& \frac{d \varepsilon_{\xi}}{d t}=Q_{V V^{\prime}}^{\xi}+Q_{V T}^{\xi}+Q_{\mathrm{ch}}^{\xi}+Q_{I}^{\xi}, \\
& \frac{d H}{d t}+\sum_{i=0}^{S} \frac{d e_{V}^{i}}{d t}=\frac{k_{\nu} I_{0}(t)}{\rho} \\
& Q_{V V^{\prime}}^{\xi}=N \sum_{p=1}^{L_{1}} \frac{l_{\xi} L_{\xi, p}}{g_{\xi}^{l_{\xi}} g_{p}^{l_{p}}} W_{\xi, p}^{\prime}, \quad Q_{V T}^{\xi}=\left(\varepsilon_{\xi 0}-\varepsilon_{\xi}\right)\left(1-y_{\xi 0}\right) \sum_{i=1}^{M_{1}} W_{\xi, 0}^{i} \gamma_{i}, \\
& Q_{\mathrm{ch}}^{\xi}=\sum_{r=1}^{L_{2, \xi}} \frac{\alpha_{\mathrm{ir}}^{-}-\alpha_{\mathrm{ir}}^{+}}{N_{i}}\left[\left(\chi_{r \xi}^{+}-\varepsilon_{\xi}\right) R_{r}^{+}-\left(\chi_{r \xi}^{-}-\varepsilon_{\xi}\right) R_{r}^{-}\right], \quad Q_{I}^{\xi}=\frac{k_{\nu} I_{0}(t)}{h \nu_{I} N_{\mathrm{O}_{3}}} \\
& L_{\xi, p}=\varepsilon_{\xi}^{l_{\xi}}\left(g_{p}+\varepsilon_{p}\right)^{l_{p}}-\varepsilon_{p}^{l_{p}}\left(g_{\xi}+\varepsilon_{\xi}\right)^{l_{\xi}} \exp \left(\frac{l_{\xi} \theta_{\xi}-l_{p} \theta_{p}}{T}\right), \\
& R_{q}^{+(-)}=k_{+(-) q} \prod_{j=1}^{n_{q}^{+(-)}} N_{j}^{\alpha_{j q}^{+(-)}}, \quad G_{i}=\sum_{q=1}^{M_{2, i}} S_{i q}, \quad S_{i q}=\frac{\alpha_{i q}^{-}-\alpha_{i q}^{+}}{N}\left(R_{q}^{+}-R_{q}^{-}\right), \\
& \chi_{r \xi}^{+(-)}=\frac{E_{r}}{K \theta_{\xi}} \eta_{r \xi}^{+(-)}, \quad \eta_{r \xi}^{+}=\frac{\beta_{r \xi}^{2}}{\sum_{i} \beta_{r i}^{2}}, \quad \eta_{r \xi}^{-}=\beta_{r \xi}^{2} T_{\xi}^{2} \sum_{i} \beta_{r i}^{2}\left(\sum_{j} \beta_{r j}^{2} T_{j}\right)^{-2}, \\
& H=\frac{1}{\mu} \sum_{i=1}^{M_{1}} h_{0, i} \gamma_{i}+\left[\frac{3}{2}+C_{R}\right] \frac{R}{\mu} T, \quad C_{R}=\sum_{i=1}^{L} \gamma_{i}+\frac{3}{2} \sum_{i=L+1}^{S} \gamma_{i}, \quad \mu=\sum_{i=1}^{M_{1}} \mu_{i} \gamma_{i}, \\
& P=\frac{\rho R T}{\mu}, \quad N=\frac{P}{K T}, \quad e_{V}^{i}=\gamma_{i} \frac{R}{\mu} \sum_{j=1}^{Z_{i}} \theta_{i j} \varepsilon_{i j}, \quad \gamma_{i}=\frac{N_{i}}{N}, \\
& \varepsilon_{\xi}=\frac{g_{\xi} y_{\xi}}{1-y_{\xi}}, \quad \varepsilon_{\xi 0}=\varepsilon_{\xi}\left(y_{\xi}=y_{\xi 0}\right),
\end{aligned}
$$

where we use the following notation:

$\rho$ and $P$ are the gas density and pressure;

$R$ is the universal gas constant;

$h_{0, i}$ is the enthalpy of formation of the $i$ th component of the mixture at $T=298 \mathrm{~K}$;

$\mu_{i}$ is its molar weight;

$S$ is the number of molecular components; 
$L$ is the number of components consisting of linear molecules;

$g_{\xi}$ is the degeneracy multiplicity of the $\xi$ th mode;

$Z_{i}$ is the number of vibration modes for molecules of the $i$ th sort;

$W_{\xi, p}^{\prime}=\sum_{i=1}^{M_{1}} W_{\xi, p}^{i} \gamma_{i}$ in the case of intramolecular VV' exchange;

$W_{\xi, p}^{\prime}=W_{\xi, p} \gamma_{i}(\xi \leftrightarrow i$ and $p \leftrightarrow j)$ in the case of intermolecular $V V^{\prime}$ exchange;

$W_{\xi, p}^{i}$ and $W_{\xi, 0}^{i}$ are the rate constants of intramolecular VV' exchange and VT relaxation for collisions with the $i$ th partner;

$W_{\xi, p}$ is the rate constant of intermolecular VV' exchange;

$N_{i}$ is the density of molecules of the $i$ th sort;

$M_{1}$ is the number of atomic and molecular components in the mixture;

$l_{\xi}$ is the number of vibrational quanta lost or gained by the mode $\xi$ during VV' exchange ( $L_{1}$ is the number of channels for VV' exchange);

$\alpha_{i q}^{+}$and $\alpha_{i q}^{-}$are the stoichiometric coefficients of the $q$ th reaction resulting in the formation of the $i$ th component;

$k_{+q}$ and $k_{-q}$ are the rate constants of the $q$ th reaction in the forward (+) and backward (-) directions;

$L_{2, \xi}$ is the number of reactions resulting in the formation (elimination) of the molecule containing the mode $\xi$

$M_{2, i}$ is the number of reactions resulting in the formation of the $i$ th component;

$\beta_{r \xi}$ are the coefficients of expansion of the $r$ th reaction in the coordinates of normal vibrations;

$E_{r}$ is the energy released into the vibrational degrees of freedom during the $r$ th reaction.

The values of $\beta_{r \xi}$, following [20], are set equal to unity.

The values of $E_{r}$ were estimated by the formulas in [20,25].

To calculate the Voight function, the coefficients $b_{c}^{M}$ of collision broadening $b_{c}=\sum_{M} b_{c}^{M} \gamma_{M}$ of the spectral line $000\left(12_{1,11}\right) \rightarrow 001\left(11_{1,10}\right)$ in the $\mathrm{O}_{3}$ molecule for $\mathrm{M}=\mathrm{N}_{2}$ were taken from [12] and for other components were estimated under the assumption that the gas-kinetic and optical cross-sections are equal.

\section{Ignition of Combustible Mixtures Exposed to Radiation}

It is known that ignition of the majority of gas mixtures occurs due to chain reactions involving highly reactive atoms and radicals. The atoms and radicals disappear from the reaction zone due to diffusion. Therefore, ignition of a gas mixture in an adiabatic reactor (or in a laser beam) of radius $R_{a}$ is possible if the condition $\tau_{i}^{\text {ch }} \leq \tau_{R, i}$ is satisfied [26]. For $\mathrm{H}_{2} /$ air $/ \mathrm{O}_{3}$ mixtures, $\tau_{i}^{\text {ch }}$ is the time of formation of reactive $\mathrm{H}$ and $\mathrm{O}$ atoms and $\mathrm{OH}$ radicals that are the chain carriers, and $\tau_{R, i}$ is the time of removal of these components from the reaction zone. In the problem considered, $\tau_{R, i}$ is the time of diffusion of the lightest reactive radicals $-\mathrm{H}$ atoms, i.e., $\tau_{R, i}=\tau_{D, \mathrm{H}}$.

The mechanism of chain process development for $\mathrm{CH}_{4} /$ air $/ \mathrm{O}_{3}$ and $\mathrm{C}_{2} \mathrm{H}_{2} /$ air $/ \mathrm{O}_{3}$ mixtures are more complicated and the chain carrier components are the following: $\mathrm{CH}_{3}, \mathrm{CH}_{2}, \mathrm{C}_{2} \mathrm{H}, \mathrm{C}_{2} \mathrm{HO}, \mathrm{OH}, \mathrm{H}$, and O. For these mixtures, $\tau_{R, i}=\tau_{D, \mathrm{O}}$. This implies that for $\tau_{i}^{\text {ch }}>\tau_{D, \mathrm{H}}\left(\right.$ or $\tau_{D, \mathrm{O}}$ ) the induction time $\tau_{\text {ind }}$ is bounded from above by the time $\tau_{D, \mathrm{H}}\left(\right.$ or $\left.\tau_{D, \mathrm{O}}\right)$ and that the ignition temperature $T_{\mathrm{ign}}$ can be determined, as a first approximation, from the relation

$$
\tau_{\text {ind }}\left(T_{\text {ign }}, P_{0}\right)=\tau_{D, i}\left(T_{\text {ign }}, P_{0}\right),
$$




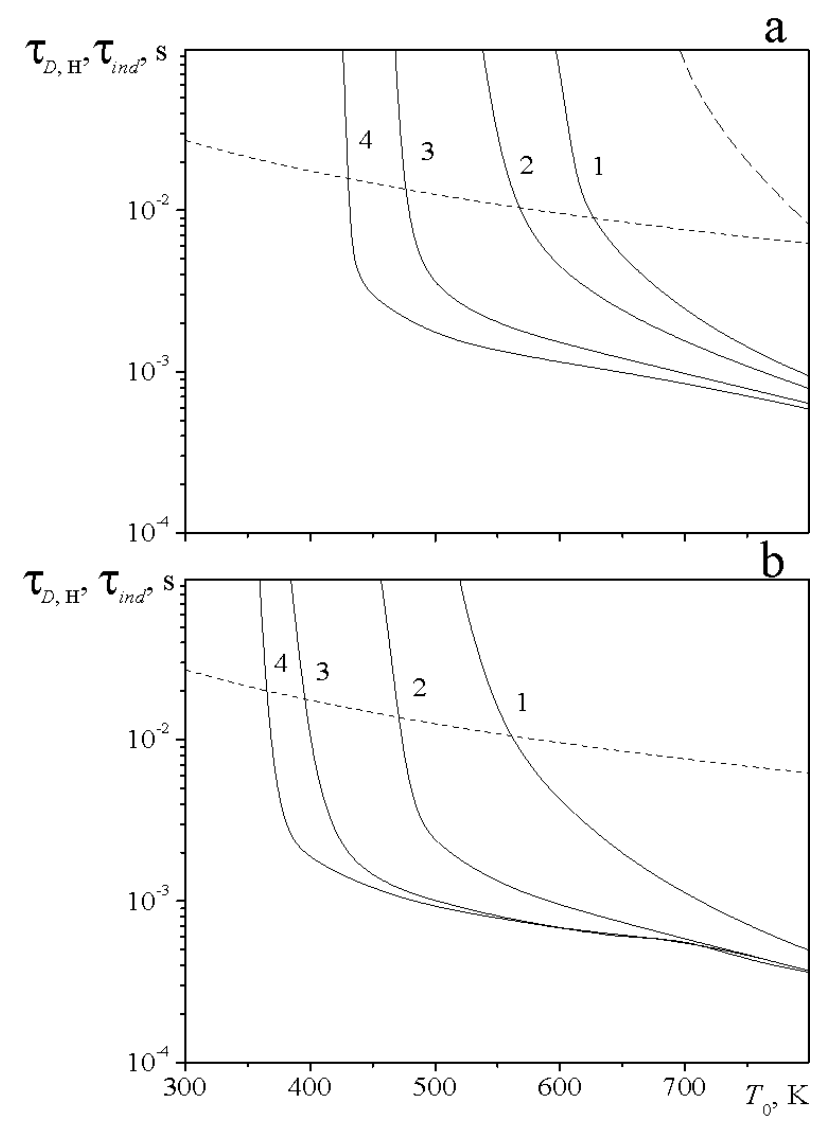

Fig. 1. Predicted dependences of $\tau_{D, \mathrm{H}}\left(T_{0}\right)$ (dotted curve) and $\tau_{\text {ind }}\left(T_{0}\right)$ (solid curves) for a stoichiometric $\mathrm{H}_{2} /$ air mixture with $\gamma_{\mathrm{O}_{3}}=0.5 \%$ (a) and $1 \%$ (b) $\left(P_{0}=10^{4} \mathrm{~Pa}\right)$ upon irradiation at $\lambda_{I} \approx 9.7 \mu \mathrm{m}, \tau_{p}=10^{-5}$ s for different values of $E_{0}: 0(1), 0.2 \mathrm{~J} / \mathrm{cm}^{2}(2), 1 \mathrm{~J} / \mathrm{cm}^{2}(3)$, and $5 \mathrm{~J} / \mathrm{cm}^{2}$ (4). Dashed curve corresponds to a pure $\mathrm{H}_{2} /$ air mixture at $E_{0}=0$.

$i=\mathrm{H}$ for $\mathrm{H}_{2} /$ air $/ \mathrm{O}_{3}$ mixture and $i=\mathrm{O}$ for $\mathrm{CH}_{4}\left(\mathrm{C}_{2} \mathrm{H}_{2}\right) /$ air $/ \mathrm{O}_{3}$ mixtures. Under laser-irradiation conditions, the quantity $\tau_{\text {ind }}$ depends not only on the composition and initial parameters of the mixture $T_{0}$ and $P_{0}$ but also on the degree of excitation of $\mathrm{O}_{3}$ molecules. The latter is determined by the radiation intensity $I_{0}$ and the pulse duration $\tau_{p}$, or by the laser-radiation-energy flux supplied to the gas $E_{0}=I_{0} \tau_{p}$. The other important parameter, which specifies the energy efficiency of the approach based on the laserinduced excitation of reactive molecules, is the specific energy absorbed by the gas $E_{a}=\int_{0}^{\tau_{p}} I_{0} k_{\nu} d t$.

\subsection{Initiation of Combustion of $\mathrm{H}_{2} /$ air $/ \mathrm{O}_{3}$ Mixture}

Figure 1 plots the curves of the induction $\tau_{\text {ind }}$ and diffusion $\tau_{D, \mathrm{H}}\left(R_{a}=1 \mathrm{~cm}\right)$ times versus the initial temperature for a stoichiometric $\mathrm{H}_{2}$ /air mixture containing 0.5 and $1 \%$ of $\mathrm{O}_{3}$ under exposure to laser radiation with different $E_{0}$ values. First of all, it is obvious that the admixture even of a small amount of ozone $\left(\gamma_{\mathrm{O}_{3}}=0.5 \%\right)$ to the $\mathrm{H}_{2}$ /air mixture results in a noticeable decrease in the induction 
time and ignition temperature. Thus, under the conditions considered, $T_{\mathrm{ign}}=825 \mathrm{~K}$ for a stoichiometric $\mathrm{H}_{2}$ /air mixture, whereas an admixture of $0.5 \% \mathrm{O}_{3}$ decreases the ignition temperature by $185 \mathrm{~K}$, and for a mixture with $\gamma_{\mathrm{O}_{3}}=1 \%, T_{\mathrm{ign}}=560 \mathrm{~K}$. Exposure to radiation even at a small value of the radiationenergy flux $E_{0}=0.2 \mathrm{~J} / \mathrm{cm}^{2}$ lowers the value of $T_{\text {ign }}$ to $570 \mathrm{~K}$ at $\gamma_{\mathrm{O}_{3}}=0.5 \%$ and to $470 \mathrm{~K}$ for a mixture with $\gamma_{\mathrm{O}_{3}}=1 \%$. An increase in $E_{0}$ results in an additional decrease in the induction time and ignition temperature. Thus, at $E_{0}=1 \mathrm{~J} / \mathrm{cm}^{2}$ for a mixture with $\gamma_{\mathrm{O}_{3}}=1 \%$, the value of $T_{\text {ign }}$ can be reduced to $400 \mathrm{~K}$. The reduction in induction time may amount to orders of magnitude. For instance, at $T_{0}=550 \mathrm{~K}$, exposure of the mixture with $\gamma_{\mathrm{O}_{3}}=0.5 \%$ to radiation with $E_{0}=0.5 \mathrm{~J} / \mathrm{cm}^{2}$ (the energy absorbed by the gas $E_{a}$ does not exceed $2 \cdot 10^{-4} \mathrm{~J} / \mathrm{cm}^{3}$ in this case) decreases the value of $\tau_{\text {ind }}$ by a factor of 70 .

The decrease in induction time with addition of ozone to the mixture arises, on the one hand, from the formation of reactive $\mathrm{O}$ atoms by dissociation of $\mathrm{O}_{3}$ molecules, which accelerates the chain reactions, and, on the other hand, from the increase in the gas temperature due to ozone combustion (most of the energy is released, in this case, in the reaction $\mathrm{O}+\mathrm{O}_{3}=2 \mathrm{O}_{2}$ ), which also activates the ignition process. The excitation of asymmetric vibrations of $\mathrm{O}_{3}$ molecules by laser radiation accelerates these processes significantly.

The nonequilibrium excitation of $\mathrm{O}_{3}$ molecule vibrations is much more effective than the simple heating of the mixture by the same amount of supplied energy. In this case, both the nature of the dependences $\gamma_{i}(t)$ and the temperature-variation dynamics change (Fig. 2). The excitation of the asymmetric mode of $\mathrm{O}_{3}$ molecules (for $t=\tau_{p}=10^{-5} \mathrm{~s}$, the vibrational temperature $T_{17}$ reaches $2170 \mathrm{~K}$ ) leads to a considerable increase in the decomposition rate of ozone, a sharp increase in the concentration of $\mathrm{O}$ atoms, and growth of the translational temperature for $t \geq 6 \cdot 10^{-4} \mathrm{~s}$ (Fig. 2c). Since the $\mathrm{O}_{3} / \mathrm{O}_{2}$ system is ignited by the mechanism of thermal explosion [25] and the $\mathrm{H}_{2} / \mathrm{O}_{2}$ (air) system by the chain reaction mechanism, the excitation of vibrations of $\mathrm{O}_{3}$ molecules in the $\mathrm{H}_{2}$ /air $/ \mathrm{O}_{3}$ system leads to activation of both mechanisms.

Recall that in $\mathrm{H}_{2} / \mathrm{O}_{2}$ (air) mixtures at low temperatures, the main chain-initiation reaction is the reaction $\mathrm{H}_{2}+\mathrm{O}_{2}=2 \mathrm{OH}$. Next, $\mathrm{OH}$ radicals react with $\mathrm{H}_{2}$ in the chain-propagation reaction $\mathrm{H}_{2}+\mathrm{OH}$ $=\mathrm{H}_{2} \mathrm{O}+\mathrm{H}$. The resulting $\mathrm{H}$ atoms participate in the chain-branching process $\mathrm{H}+\mathrm{O}_{2}=\mathrm{OH}+\mathrm{O}$. The $\mathrm{O}$ atoms interact with $\mathrm{H}_{2}$ molecules by the reaction $\mathrm{O}+\mathrm{H}_{2}=\mathrm{OH}+\mathrm{H}$ to produce $\mathrm{H}$ atoms again and are thus the major carriers of the chain-ignition mechanism.

In the $\mathrm{H}_{2} / \mathrm{O}_{2}$ (air) $/ \mathrm{O}_{3}$ mixture, a novel channel of the O-atom formation appears. It is the reaction of ozone dissociation $\mathrm{O}_{3}+\mathrm{M}=\mathrm{O}+\mathrm{O}_{2}+\mathrm{M}$. This reaction is rather slow at low temperatures $T_{0}=500$ $600 \mathrm{~K}$ (see Fig. 2a). That is why there is no ignition in the stoichiometric $\mathrm{H}_{2} /$ air $/ \mathrm{O}_{3}$ mixture with $\gamma_{\mathrm{O}_{3}}=0.5 \%$ at $T_{0}=600 \mathrm{~K}$ and $P_{0}=10^{4} \mathrm{~Pa}$ (in this case, $\tau_{\text {ind }}>\tau_{D, \mathrm{H}}$ ). The heating of the gas by laser radiation (for absorbed energy $E_{a}=9.4 \cdot 10^{-4} \mathrm{~J} / \mathrm{cm}^{3}$ and $T_{0}=600 \mathrm{~K}$, the temperature increases up to $657 \mathrm{~K}$ ) results in acceleration of ozone dissociation and growth of the O-atom concentration. This enhances the chain process and decreases the induction time (Fig. 2b). In this case, $\tau_{\text {ind }}<\tau_{D, \mathrm{H}}$ and ignition occurs under the conditions considered. In the case of excitation of $\mathrm{O}_{3}$ molecular vibrations, the reaction $\mathrm{O}_{3}(001)+\mathrm{M}=\mathrm{O}+\mathrm{O}_{2}+\mathrm{M}$ becomes the main chain-initiation reaction. The resulting oxygen atoms, on the one hand, directly participate in chain process and, on the other hand, initiate the exothermic reaction $\mathrm{O}+\mathrm{O}_{3}=2 \mathrm{O}_{2}$, which leads to an increase in the gas temperature, and hence, to an additional increase in the chain-reaction rate. The reaction $\mathrm{O}_{3}(001)+\mathrm{H}_{2}=\mathrm{OH}+\mathrm{HO}_{2}$ àlso makes a certain contribution to the activation of the chain mechanism. In this case, the significant enhancement of chain process appears. This results in the much greater decrease in the value of $\tau_{\text {ind }}$ as compared to the case of heating the mixture by laser radiation. 


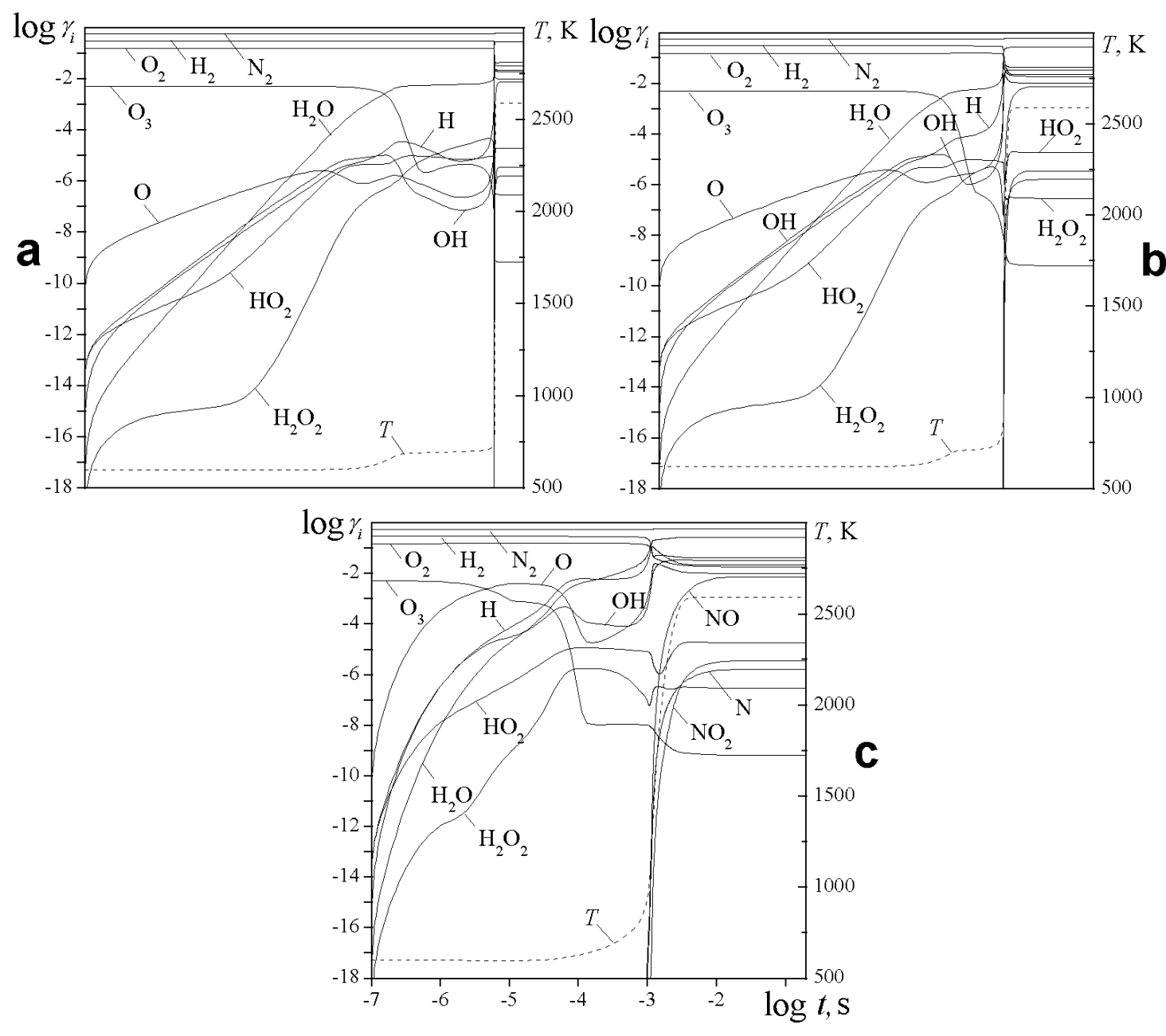

Fig. 2. Temporal evolution of species molar fractions (solid curves) and gas temperature (dashed curves) during ignition of a stoichiometric $\mathrm{H}_{2} /$ air $/ \mathrm{O}_{3}$ mixture for $\gamma_{\mathrm{O}_{3}}=0.5 \%, P_{0}=10^{4} \mathrm{~Pa}$ and $T_{0}=600 \mathrm{~K}$ in the absence of the radiation (a); the entire radiation energy absorbed by ozone $\left(E_{a}=9.4 \cdot 10^{-4} \mathrm{~J} / \mathrm{cm}^{3}\right)$ is consumed in heating the mixture (b); the nonequilibrium excitation of asymmetric vibrations of $\mathrm{O}_{3}$ molecules by radiation (c) with $\lambda_{I} \approx 9.7 \mu \mathrm{m}, E_{a}=9.4 \cdot 10^{-4} \mathrm{~J} / \mathrm{cm}^{3}$, and $\tau_{p}=10^{-5} \mathrm{~s}$.

The benefit of the reduction in induction time for the case of laser-induced excitation of the asymmetric mode of $\mathrm{O}_{3}$ molecules as compared to the case of heating the mixture by laser radiation increases with decreasing initial temperature. Figure 3 shows the predicted variation in the gas temperature during the ignition of stoichiometric $\mathrm{H}_{2} /$ air $/ \mathrm{O}_{3}$ mixture with $\gamma_{\mathrm{O}_{3}}=0.5 \%$ at $T_{0}=500 \mathrm{~K}$ and $P_{0}=10^{4} \mathrm{~Pa}$ upon exposure to laser radiation at various values of the energy absorbed by a single $\mathrm{O}_{3}$ molecule $\left(E_{s}=E_{a} / N_{\mathrm{O}_{3}}\right)$ for both cases considered. One can see that in both cases an increase in the radiation energy delivered to the ozone reduces the induction and combustion times. From the plots shown in Fig. 3 it follows that the difference in the values of induction time for the case of nonequilibrium excitation of the asymmetric mode of $\mathrm{O}_{3}$ molecule vibrations and for the case of heating of the mixture by laser radiation 


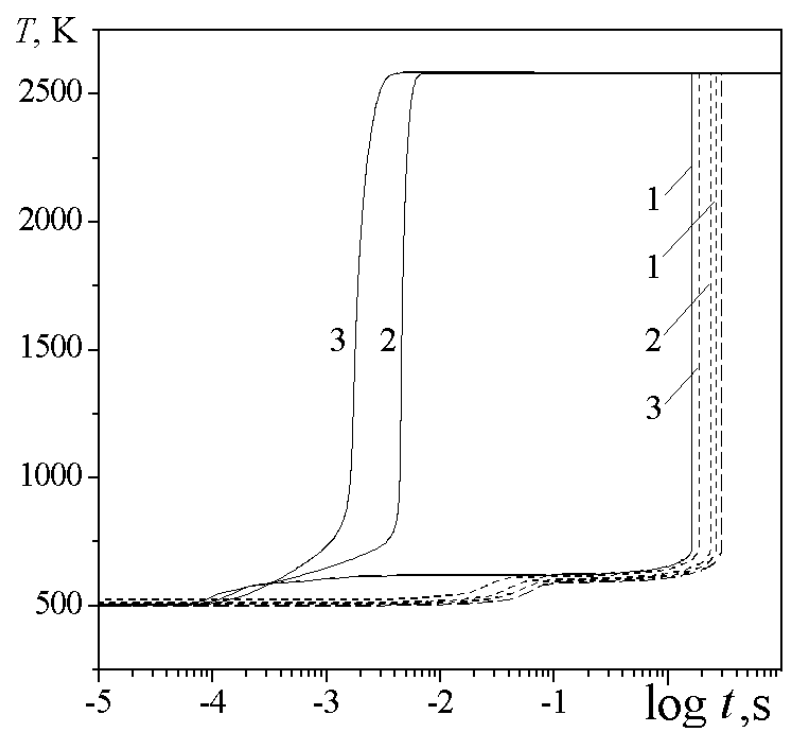

Fig. 3. Gas temperature versus time for ignition of a stoichiometric $\mathrm{H}_{2} /$ air $/ \mathrm{O}_{3}$ mixture with $0.5 \% \mathrm{O}_{3}\left(T_{0}=500 \mathrm{~K}\right.$, $P_{0}=10^{4} \mathrm{~Pa}$ ) for the two cases - the entire radiation energy absorbed by ozone is consumed in heating the mixture (dotted curves) and the nonequilibrium excitation of $\mathrm{O}_{3}$ molecular vibrations by radiation at $\lambda_{I} \approx 9.7 \mu \mathrm{m}$ (solid curves) for $E_{s}=0.25 ; 0.5 ; 1 \mathrm{eV} /$ molecule $\mathrm{O}_{3}$ (curves 1,2 , and 3 , respectively), $\tau_{p}=10^{-5} \mathrm{~s}$. Dashed curve corresponds to the absence of radiation.

reaches a factor of $10^{3}$ at $T_{0}=500 \mathrm{~K}$ and $E_{s}=1 \mathrm{eV} /\left(\right.$ molecule $\left.\mathrm{O}_{3}\right)\left(E_{a}=1.1 \cdot 10^{-3} \mathrm{~J} / \mathrm{cm}^{3}\right)$. However, at $E_{s}=0.25 \mathrm{eV} /\left(\right.$ molecule $\left.\mathrm{O}_{3}\right)$ this difference does not exceed 3 times.

It should be noted that a decrease in the induction time may be achieved by increasing the initial temperature, i.e., by heating the gas. For example, in order to reduce the value of $\tau_{\text {ind }}$ to $1.7 \cdot 10^{-3} \mathrm{~s}$ in a stoichiometric $\mathrm{H}_{2} /$ air $/ \mathrm{O}_{3}$ mixture with $\gamma_{\mathrm{O}_{3}}=0.5 \%$ at $T_{0}=500 \mathrm{~K}$, it is needed to excite the asymmetric mode of $\mathrm{O}_{3}$ molecules with radiation energy $E_{a}=1.2 \cdot 10^{-3} \mathrm{~J} / \mathrm{cm}^{3}$. Another way to obtain the same value of $\tau_{\text {ind }}$ is to heat the mixture up to $T_{h}=715 \mathrm{~K}$.

Let us compare the following two quantities - the chemical energy $\Delta H_{\mathrm{ch}}^{I}$, which is released as a heat during low-temperature combustion $\left(T_{0}=500 \mathrm{~K}\right)$ of a $\mathrm{H}_{2} /$ air $/ \mathrm{O}_{3}$ mixture with $\gamma_{\mathrm{O}_{3}}=0.5 \%$ and $P_{0}=$ $10^{4} \mathrm{~Pa}$ initiated by $9.7 \mu \mathrm{m}$ radiation at $E_{m}=E_{a} / \rho=23.9 \mathrm{~J} / \mathrm{g}$, and the corresponding value $\Delta H_{\mathrm{ch}}^{T}$, which is released in conventional high-temperature combustion that ensures the same value of induction time as laser-induced excitation of vibrations of the $\mathrm{O}_{3}$ molecule. Calculations show that $\Delta H_{\mathrm{ch}}^{I}=2.48 \cdot 10^{3} \mathrm{~J} / \mathrm{g}$ and $\Delta H_{\mathrm{ch}}^{T}=2.34 \cdot 10^{3} \mathrm{~J} / \mathrm{g}$. Thus, with the inclusion of radiation energy that is absorbed by the gas and the thermal energy $E_{T}=214 \mathrm{~J} / \mathrm{g}$ that is required to increase the gas temperature up to $T_{h}=715 \mathrm{~K}$, the chemical energy of the system is used with a higher efficiency in the case of low-temperature combustion initiated by laser-induced excitation of ozone molecules $\left(\Delta H_{\mathrm{ch}}^{I}-E_{m}>\Delta H_{\mathrm{ch}}^{T}-E_{T}\right)$. Under the conditions considered, the energy gain is $\sim 15 \%$.

\subsection{Initiation of Combustion of $\mathrm{CH}_{4} / \mathrm{Air} / \mathrm{O}_{3}$ and $\mathrm{C}_{2} \mathrm{H}_{2} / \mathrm{Air} / \mathrm{O}_{3}$ Mixtures}

It is known that methane exhibits the greatest ignition delay time as compared to other hydrocarbons, especially acetylene. Admixture of ozone molecules to $\mathrm{C}_{2} \mathrm{H}_{2}$ /air and $\mathrm{CH}_{4}$ /air mixtures leads to a 

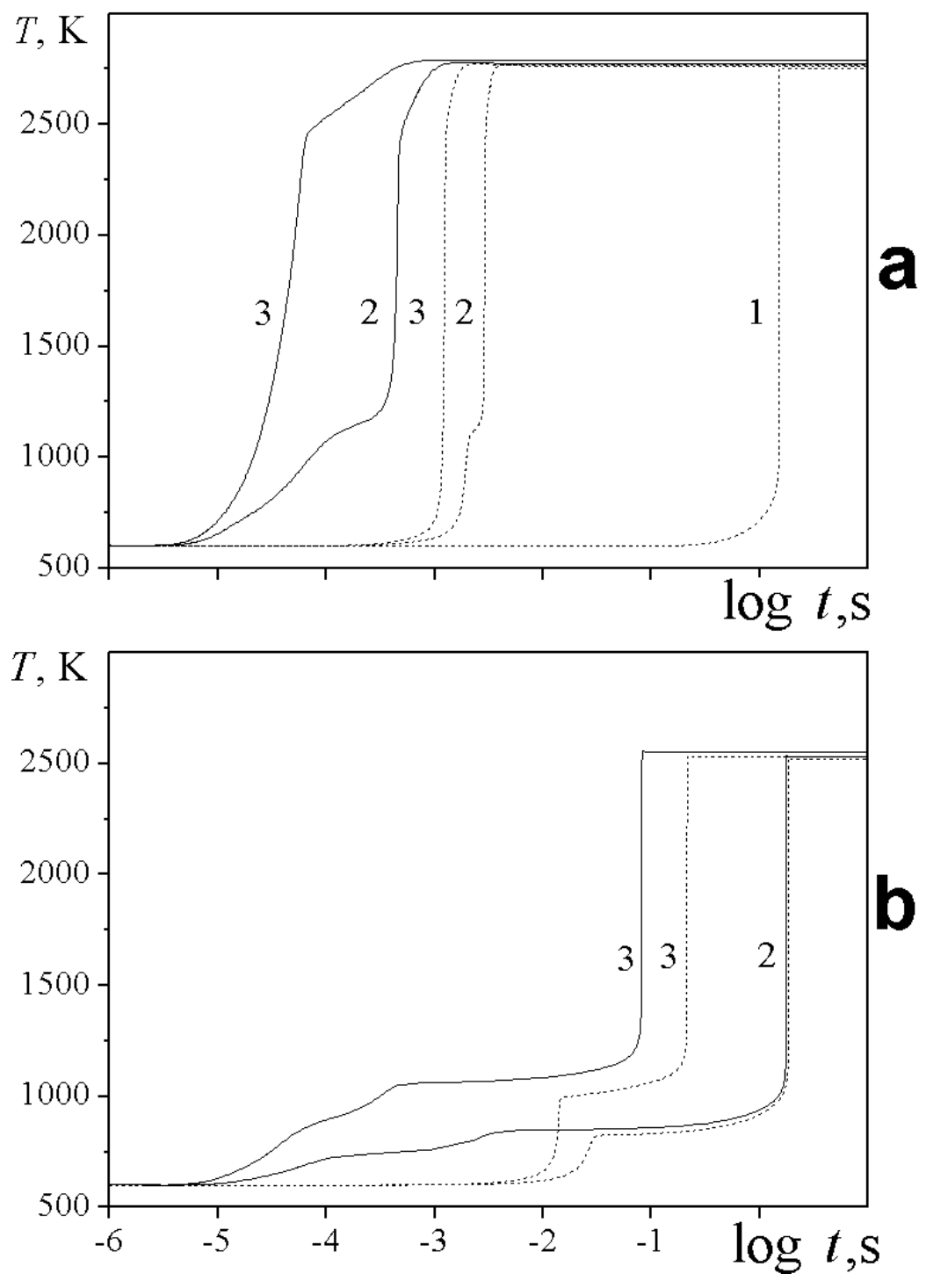

Fig. 4. Gas temperature versus time for ignition of stoichiometric $\mathrm{C}_{2} \mathrm{H}_{2} /$ air $/ \mathrm{O}_{3}$ (a) and $\mathrm{CH}_{4} /$ air $/ \mathrm{O}_{3}$ (b) mixtures with $\gamma_{\mathrm{O}_{3}}=0 ; 2.5 ; 5 \%$ (curves 1,2 , and 3 , respectively) at $T_{0}=600 \mathrm{~K}$ and $P_{0}=10^{4} \mathrm{~Pa}$ upon irradiation at $\lambda_{I} \approx 9.7 \mu \mathrm{m}, \tau_{p}=10^{-5} \mathrm{~s}$ for $E_{0}=0$ and $1 \mathrm{~J} / \mathrm{cm}^{2}$ (dotted and solid curves, respectively). Curve 1 in the below panel is not shown since $\tau_{\text {ind }}>1 \mathrm{~s}$.

significant decrease in the ignition delay time (induction time) as well as for $\mathrm{H}_{2} /$ air mixture. However, the amount of ozone admixed to the $\mathrm{CH}_{4}\left(\mathrm{C}_{2} \mathrm{H}_{2}\right)$ /air mixtures should be greater than that required for the $\mathrm{H}_{2}$ /air mixture. The main reason for the decrease in the induction time for $\mathrm{CH}_{4}\left(\mathrm{C}_{2} \mathrm{H}_{2}\right)$ /air mixtures with admixture of $\mathrm{O}_{3}$ molecules is similar to that for $\mathrm{H}_{2}$ /air mixture and is caused by $\mathrm{O}$-atom formation during ozone decomposition. Oxygen atoms react with primary hydrocarbon molecules $\mathrm{CH}_{4}$ or $\mathrm{C}_{2} \mathrm{H}_{2}$ :

$$
\mathrm{CH}_{4}+\mathrm{O}=\mathrm{CH}_{3}+\mathrm{OH} \quad \text { or } \quad \mathrm{C}_{2} \mathrm{H}_{2}+\mathrm{O}=\mathrm{CH}_{2}+\mathrm{CO}, \quad \mathrm{C}_{2} \mathrm{H}_{2}+\mathrm{O}=\mathrm{C}_{2} \mathrm{HO}+\mathrm{H} \text {. }
$$


As a result, in the $\mathrm{CH}_{4}\left(\mathrm{C}_{2} \mathrm{H}_{2}\right)$ /air/ $\mathrm{O}_{3}$ mixture, highly reactive radicals $\mathrm{CH}_{3}\left(\mathrm{CH}_{2}\right)$ and $\mathrm{OH}(\mathrm{H})$ form and initiate the chain processes. The increase in temperature due to the energy release in the reaction $\mathrm{O}+\mathrm{O}_{3}=2 \mathrm{O}_{2}$ additionally accelerates the processes of formation of reactive radicals.

The excitation of asymmetric vibrations of $\mathrm{O}_{3}$ molecules enhances these processes significantly. This is clearly seen from the plots of temporal evolution of gas temperature for $\mathrm{CH}_{4} /$ air $/ \mathrm{O}_{3}$ and $\mathrm{C}_{2} \mathrm{H}_{2} /$ air $/ \mathrm{O}_{3}$ mixtures shown in Fig. 4. One can conclude that exposure of the $\mathrm{C}_{2} \mathrm{H}_{2} /$ air $/ \mathrm{O}_{3}$ mixture to radiation with $\lambda_{I} \approx 9.7 \mu \mathrm{m}$ results in a larger decrease in induction time than that for the $\mathrm{CH}_{4} /$ air $/ \mathrm{O}_{3}$ mixture. This behavior is caused by the larger difference in the values of the characteristic time of asymmetric-mode vibrational-energy relaxation in $\mathrm{O}_{3}$ molecule $\tau_{\mathrm{O}_{3}}$ and the time of the chemical reactions, which result in the formation of reactive radicals - carriers of chain process $\tau_{\mathrm{i}, \mathrm{r}}^{\mathrm{ch}}$ for $\mathrm{CH}_{4} /$ air $/ \mathrm{O}_{3}$ mixture, as compared to values that are characteristic for $\mathrm{C}_{2} \mathrm{H}_{2} /$ air $/ \mathrm{O}_{3}$ mixture.

For the $\mathrm{CH}_{4} /$ air $/ \mathrm{O}_{3}$ mixture, the condition $\tau_{\mathrm{O}_{3}}<\tau_{\mathrm{i}, \mathrm{r}}^{\text {ch }}$ is met, i.e., in methane/oxygen(air) mixtures, the $\mathrm{O}$ atoms produced due to ozone decomposition recombine rapidly and have no chance to react with $\mathrm{CH}_{4}$. The level of excitation of $\mathrm{O}_{3}$ molecule vibrations, in this case, is not sufficient to intensify the dissociation of ozone molecules considerably and to produce the proper amount of $\mathrm{O}$ atoms.

For the $\mathrm{C}_{2} \mathrm{H}_{2} /$ air $/ \mathrm{O}_{3}$ mixture, the condition $\tau_{\mathrm{O}_{3}} \approx \tau_{\mathrm{i}, \mathrm{r}}^{\text {ch }}$ is satisfied and a large amount of $\mathrm{O}$ atoms forms due to ozone decomposition. These atoms rather rapidly react with $\mathrm{C}_{2} \mathrm{H}_{2}$ molecules, resulting in the appearance of highly reactive radicals $\mathrm{CH}_{2}$. Moreover, the vibrationally excited ozone molecules can react directly with $\mathrm{C}_{2} \mathrm{H}_{2}$ according to the reaction $\mathrm{C}_{2} \mathrm{H}_{2}+\mathrm{O}_{3}(001)=\mathrm{CH}_{2} \mathrm{O}+\mathrm{CO}_{2}$, giving rise to the highly reactive $\mathrm{CH}_{2} \mathrm{O}$ radicals, which are carriers of chain mechanism for ignition in both $\mathrm{C}_{2} \mathrm{H}_{2} /$ air and $\mathrm{CH}_{4}$ /air mixtures.

Thus, in the case where the condition $\tau_{\mathrm{O}_{3}} \ll \tau_{\mathrm{i}, \mathrm{r}}^{\text {ch }} \sim \tau_{\text {ind }}$ is met, the effect of nonequilibrium excitation of asymmetric vibrations of $\mathrm{O}_{3}$ molecules on the induction time for $\mathrm{C}_{n} \mathrm{H}_{m} /$ air $/ \mathrm{O}_{3}$ mixture should be comparable with the influence of simple heating of the gas by laser radiation. This tendency is illustrated in Fig. 5 where the temporal variation in the species concentrations and gas temperature in a stoichiometric $\mathrm{CH}_{4} /$ air $/ \mathrm{O}_{3}$ mixture with $\gamma_{\mathrm{O}_{3}}=5 \%, T_{0}=600 \mathrm{~K}$, and $P_{0}=10^{4} \mathrm{~Pa}$ under exposure to the laser radiation are shown for the two cases - (1) the nonequilibrium excitation of $\mathrm{O}_{3}$ molecular vibrations and (2) the heating of the gas for the same absorbed energy $E_{a}=9.3 \cdot 10^{-3} \mathrm{~J} / \mathrm{cm}^{3}$. One can see that the difference in the value of $\tau_{\text {ind }}$ for the cases (1) and (2) does not exceed a factor of 3 and is significantly smaller than that one for $\mathrm{H}_{2} /$ air $/ \mathrm{O}_{3}$ mixtures. Nevertheless, the laser-induced excitation of the asymmetric mode of $\mathrm{O}_{3}$ molecules makes it possible to intensify the ignition in the $\mathrm{CH}_{4} /$ air $/ \mathrm{O}_{3}$ mixture and to decrease the induction time as compared to the case of heating the gas by laser radiation.

For the $\mathrm{C}_{2} \mathrm{H}_{2} /$ air $/ \mathrm{O}_{3}$ mixture, the characteristic time of the highly reactive radical formation is of the same order of magnitude as the time of vibrational energy relaxation for the $\nu_{17}$ mode of ozone molecule, i.e., the $\tau_{\mathrm{O}_{3}} \approx \tau_{\mathrm{i}, \mathrm{r}}^{\mathrm{ch}} \sim \tau_{\text {ind }}$. That is why the influence of the laser-induced excitation of ozone molecules on the rate of chain processes and on the reduction in $\tau_{\text {ind }}$ value is much higher than that for the case where the entire radiation energy absorbed by ozone is consumed in heating the $\mathrm{C}_{2} \mathrm{H}_{2} /$ air $/ \mathrm{O}_{3}$ mixture. Figure 6 shows the variation in the concentrations of the mixture components and in the gas temperature during low-temperature $\left(T_{0}=400 \mathrm{~K}\right)$ ignition of a stoichiometric $\mathrm{C}_{2} \mathrm{H}_{2} /$ air $/ \mathrm{O}_{3}$ mixture with $\gamma_{\mathrm{O}_{3}}=5 \%$ and $P_{0}=10^{4} \mathrm{~Pa}$ for both cases considered - the laser-induced excitation of ozone molecules and the heating of the mixture by laser radiation for the same value of absorbed energy $E_{a}=5.5 \cdot 10^{-3} \mathrm{~J} / \mathrm{cm}^{3}$. It is worth noting that in the absence of irradiation at such a low value of $T_{0}$, there is no ignition in the $\mathrm{C}_{2} \mathrm{H}_{2} /$ air $/ \mathrm{O}_{3}$ mixture.

One can see that for the $\mathrm{C}_{2} \mathrm{H}_{2} /$ air $/ \mathrm{O}_{3}$ mixture in both cases (Fig. 6) the decrease in the concentrations 

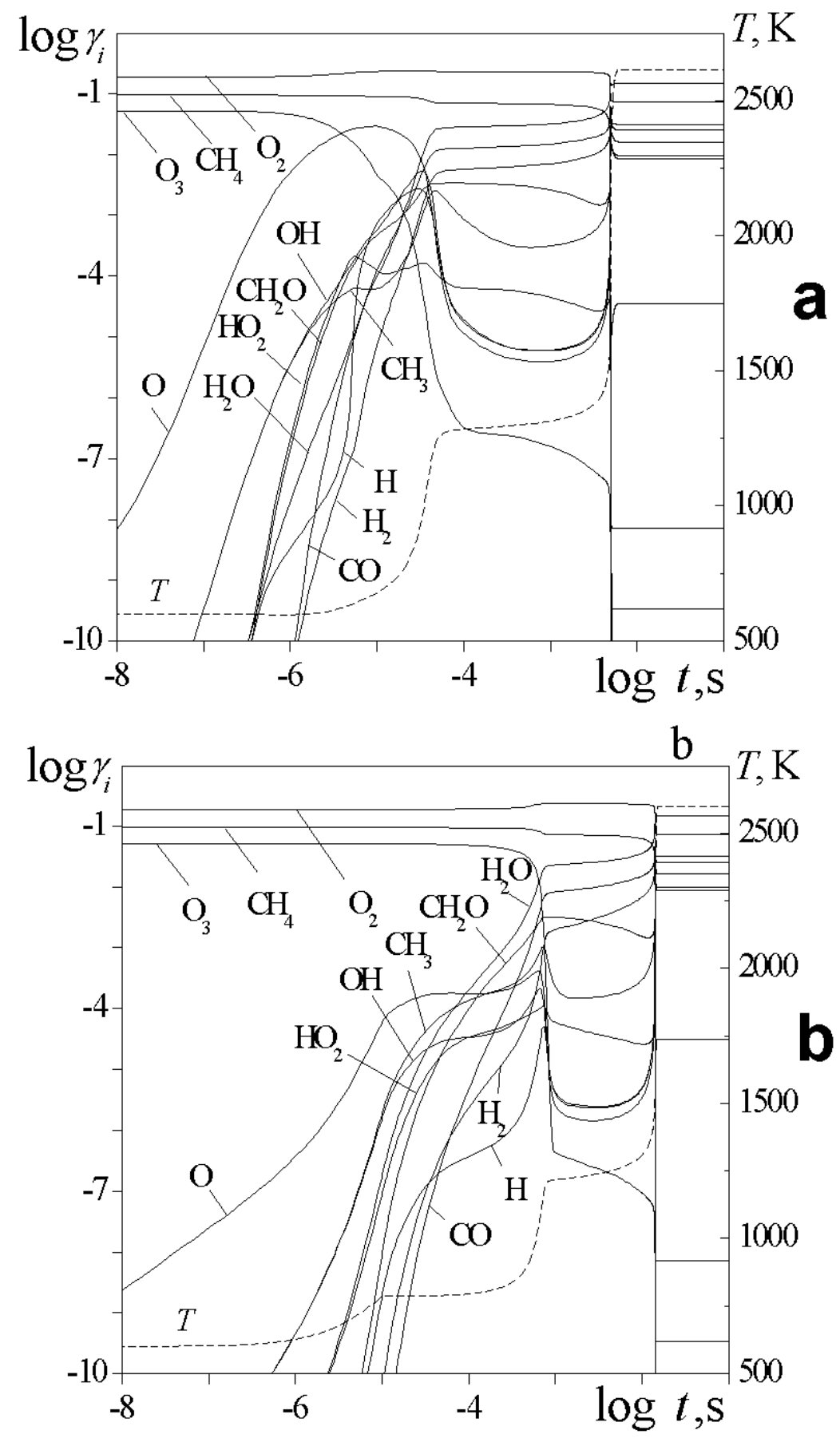

Fig. 5. Temporal evolution of species molar fractions (solid curves) and gas temperature (dashed curves) during ignition of a stoichiometric $\mathrm{CH}_{4} / \mathrm{air} / \mathrm{O}_{3}$ mixture with $\gamma_{\mathrm{O}_{3}}=5 \%, P_{0}=10^{4} \mathrm{~Pa}$, and $T_{0}=600 \mathrm{~K}$ in the two cases - (1) the nonequilibrium excitation of asymmetric vibrations of $\mathrm{O}_{3}$ molecules by radiation at $\lambda_{I} \approx 9.7 \mu \mathrm{m}$, $E_{a}=9.3 \cdot 10^{-3} \mathrm{~J} / \mathrm{cm}^{3}$, and $\tau_{p}=10^{-5} \mathrm{~s}$ (a) and (2) the entire radiation energy absorbed by ozone is consumed in heating the mixture $E_{a}=9.3 \cdot 10^{-3} \mathrm{~J} / \mathrm{cm}^{3}(\mathrm{~b})$. 

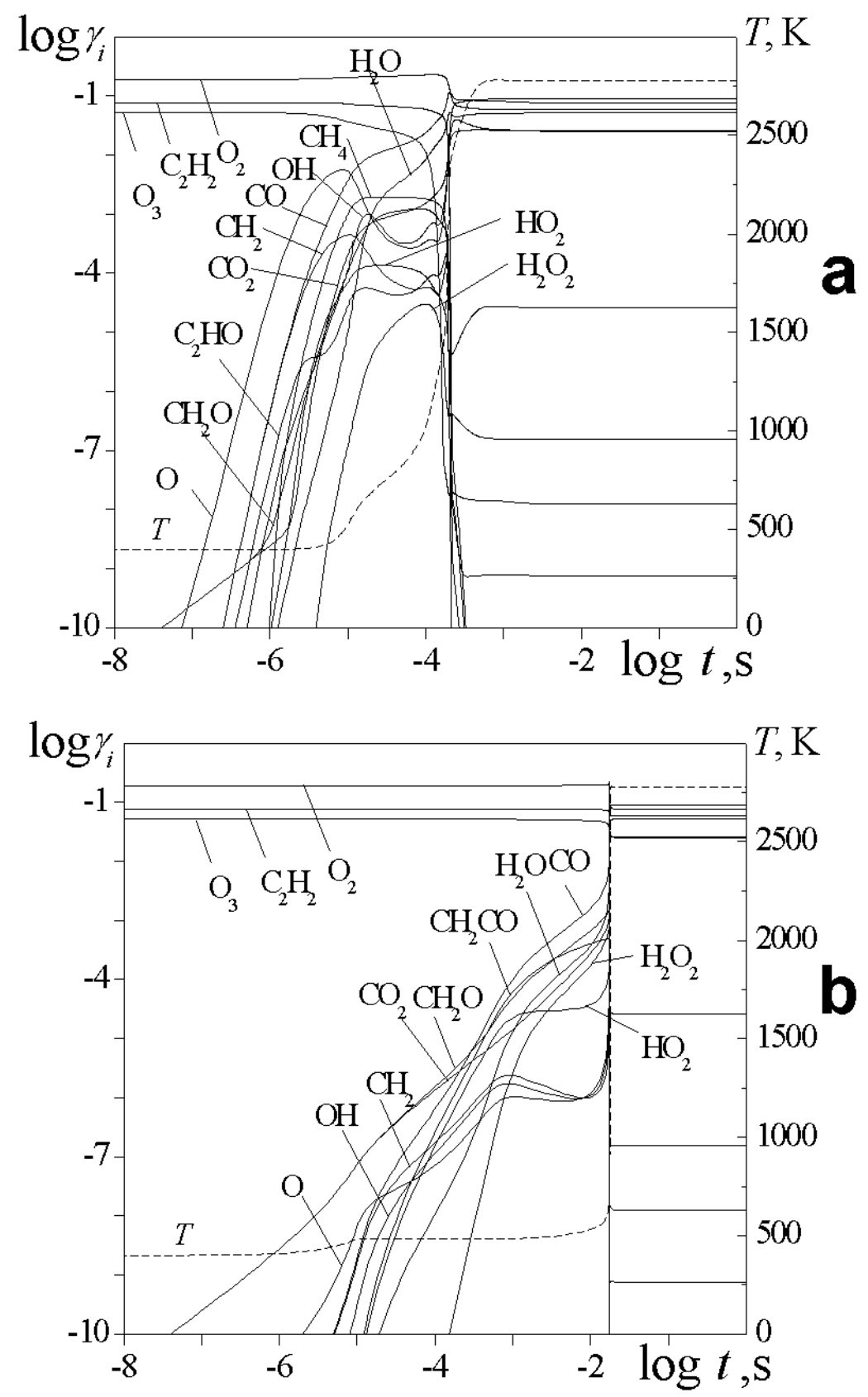

Fig. 6. Temporal evolution of species molar fractions (solid curves) and gas temperature (dashed curves) during ignition of a stoichiometric $\mathrm{C}_{2} \mathrm{H}_{2} /$ air $/ \mathrm{O}_{3}$ mixture for $\gamma_{\mathrm{O}_{3}}=5 \%, P_{0}=10^{4} \mathrm{~Pa}$, and $T_{0}=400 \mathrm{~K}$ in the two cases - (1) the nonequilibrium excitation of asymmetric vibrations of $\mathrm{O}_{3}$ molecules by radiation at $\lambda_{I} \approx 9.7 \mu \mathrm{m}$, $E_{a}=5.5 \cdot 10^{-3} \mathrm{~J} / \mathrm{cm}^{3}$, and $\tau_{p}=10^{-5} \mathrm{~s}$ (a) and (2) the entire radiation energy absorbed by ozone is consumed in heating the mixture $E_{a}=5.5 \cdot 10^{-3} \mathrm{~J} / \mathrm{cm}^{3}(\mathrm{~b})$. 
of active radicals $\mathrm{CH}_{2}, \mathrm{OH}, \mathrm{CH}_{2} \mathrm{O}$, and atoms $\mathrm{O}, \mathrm{H}$ at the time moments $t>\tau_{p}$ is considerably smaller than that for the $\mathrm{CH}_{4} /$ air $/ \mathrm{O}_{3}$ mixture (Fig. 5). In the case of nonequilibrium excitation of asymmetric vibrations of ozone molecules $\left(E_{a}=5.5 \cdot 10^{-3} \mathrm{~J} / \mathrm{cm}^{3}\right)$, for the $\mathrm{C}_{2} \mathrm{H}_{2} /$ air $/ \mathrm{O}_{3}$ mixture with $\gamma_{\mathrm{O}_{3}}=5 \%$, $T_{0}=400 \mathrm{~K}$, and $P_{0}=10^{4} \mathrm{~Pa}$, the induction time is as small as $2 \cdot 10^{-4} \mathrm{~s}$. In the case of heating the gas by laser radiation $\left(E_{a}=5.5 \cdot 10^{-3} \mathrm{~J} / \mathrm{cm}^{3}\right)$, the variations in the species concentrations and in the gas temperature are much slower. This is caused by the smaller concentrations of highly reactive radicals and atoms up to the moment $t=\tau_{p}$; the value of $\tau_{\text {ind }}$ in this case is as large as $2 \cdot 10^{-2} \mathrm{~s}$. This value of $\tau_{\text {ind }}$ is a factor of 100 larger than that for the case of nonequilibrium excitation of asymmetric vibrations of $\mathrm{O}_{3}$ molecules. It is worth noting that, in contrast to the $\mathrm{CH}_{4} /$ air $/ \mathrm{O}_{3}$ mixture, growth of the $\mathrm{O}_{2}$ concentration at $t>\tau_{p}=10^{-5} \mathrm{~s}$ does not appear. This proves that $\mathrm{O}$ atoms formed due to dissociation of vibrationally excited $\mathrm{O}_{3}$ molecules in the case of exposure of the mixture to laser radiation rapidly react with $\mathrm{C}_{2} \mathrm{H}_{2}$ and $\mathrm{CH}_{2}$ and do not recombine to form $\mathrm{O}_{2}$ molecules.

Let us consider now how the excitation of the asymmetric mode of $\mathrm{O}_{3}$ molecules by laser photons $\left(\lambda_{I} \approx 9.7 \mu \mathrm{m}\right)$ affects the ignition temperature $T_{\text {ign }}$ for $\mathrm{C}_{2} \mathrm{H}_{2} /$ air $/ \mathrm{O}_{3}$ mixture. Figure 7 depicts the dependences of induction time $\tau_{\text {ind }}$ and diffusion time $\tau_{D, \mathrm{O}}\left(R_{a}=1 \mathrm{~cm}\right)$ as a function of initial temperature for a stoichiometric $\mathrm{C}_{2} \mathrm{H}_{2}$ /air mixture containing $5 \% \mathrm{O}_{3}$ (molar fraction) at $P_{0}=10^{4} \mathrm{~Pa}$ upon exposure to laser photons with various values of the radiation-energy flux for the two approaches of the radiation energy supply: (1) the laser-induced excitation of $\mathrm{O}_{3}$ molecular vibrations and (2) the heating of the mixture by laser radiation. From the plots shown in Fig. 7 it follows that the nonequilibrium excitation of the asymmetric mode of $\mathrm{O}_{3}$ molecules is much more effective in decreasing the ignition temperature than the simple heating of the gas by laser radiation. For a stoichiometric $\mathrm{C}_{2} \mathrm{H}_{2} /$ air $/ \mathrm{O}_{3}$ mixture with $\gamma_{\mathrm{O}_{3}}=5 \%$ and $P_{0}=10^{4} \mathrm{~Pa}$, the heating of the mixture by laser radiation with $E_{0}=0.2 \mathrm{~J} / \mathrm{cm}^{2}$ decreases the value of $T_{\text {ign }}$ by $60 \mathrm{~K}$ only. In contrast, the laser-induced excitation of $\mathrm{O}_{3}$-molecule vibrations for the same value of $E_{0}$ makes it possible to lower the ignition temperature to $300 \mathrm{~K}$. It is worth noting that the difference in the values of $\tau_{\text {ind }}$ for the two considered approaches of radiation-energy supply to the mixture increases with decreasing initial temperature. For $E_{0}=0.5 \mathrm{~J} / \mathrm{cm}^{2}$ and $T_{0}=800 \mathrm{~K}$, this difference is as small as a factor of 2.5 , while at $T_{0}=400 \mathrm{~K}$ the induction time in the case of nonequilibrium excitation of the asymmetric mode of $\mathrm{O}_{3}$-molecule vibrations is a factor of 100 smaller than that for the case where the entire radiation energy absorbed by ozone is consumed in heating the mixture. This tendency is explained by the fact that at high temperatures the contribution of the vibrational energy of the $\mathrm{O}_{3}$ molecule in overcoming the barrier of endoergic reactions is not as large compared to the translational energy of the molecules as at low temperatures.

Let us compare now the efficiency of chemical energy release for the $\mathrm{C}_{2} \mathrm{H}_{2} /$ air $/ \mathrm{O}_{3}$ mixture with $\gamma_{\mathrm{O}_{3}}=5 \%$ for low-temperature combustion initiated by laser-induced excitation of $\mathrm{O}_{3}$ molecule vibrations and for ordinary high-temperature combustion initiated by heating the mixture. In order to reduce the induction time for a stoichiometric $\mathrm{C}_{2} \mathrm{H}_{2} /$ air $/ \mathrm{O}_{3}$ mixture with $\gamma_{\mathrm{O}_{3}}=5 \%$ and $P_{0}=10^{4} \mathrm{~Pa}$ at $T_{0}=400 \mathrm{~K}$ to $8.4 \cdot 10^{-5} \mathrm{~s}$ it is needed to excite the asymmetric vibrations of $\mathrm{O}_{3}$ molecules by laser radiation at $\lambda_{I} \approx 9.7 \mu \mathrm{m}$ with energy $E_{m}=88.5 \mathrm{~J} / \mathrm{g}$. In this case, the estimated chemical energy $\Delta H_{\mathrm{ch}}^{I}$ released as heat during low-temperature combustion $\left(T_{0}=400 \mathrm{~K}\right)$ reaches $2.25 \cdot 10^{3} \mathrm{~J} / \mathrm{g}$. It is possible to ignite the mixture with the same value of $\tau_{\text {ind }}$ by heating the gas up to the temperature $T_{h}=860 \mathrm{~K}$ (the required thermal energy $E_{T}$ is $366 \mathrm{~J} / \mathrm{g}$ ). In this case, the chemical energy release is smaller, $\Delta H_{\mathrm{ch}}^{T}=2.04 \cdot 10^{3} \mathrm{~J} / \mathrm{g}$. Thus, $\Delta H_{\mathrm{ch}}^{I}-E_{m}>\Delta H_{\mathrm{ch}}^{T}-E_{T}$. Under the conditions considered, the energy gain is as large as $30 \%$. This value is a factor of 2 larger than that for the $\mathrm{H}_{2} /$ air $/ \mathrm{O}_{3}$ mixture. Obviously, for the $\mathrm{CH}_{4} /$ air $/ \mathrm{O}_{3}$ mixture, the gain in chemical energy released in heating during low-temperature combustion is significantly smaller. 


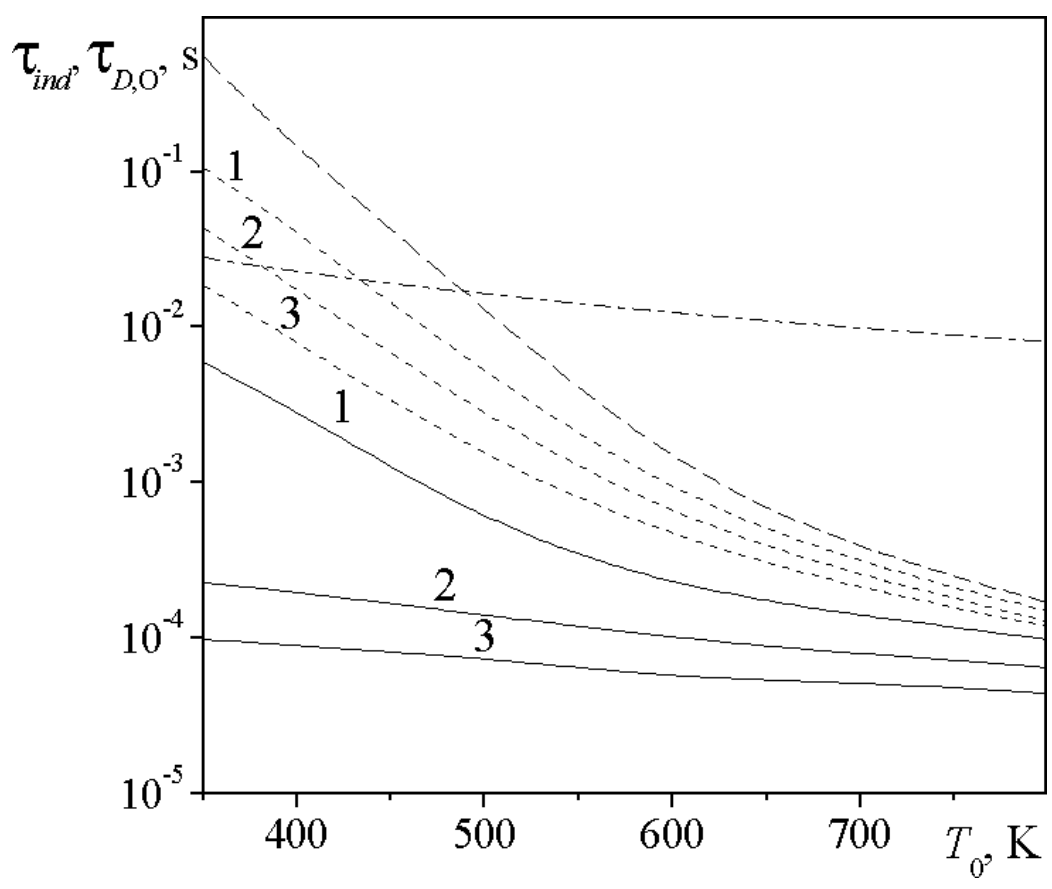

Fig. 7. Predicted dependences of $\tau_{D, \mathrm{O}}\left(T_{0}\right)$ (dash-dotted curve) and $\tau_{\text {ind }}\left(T_{0}\right)$ upon exposure of the $\mathrm{CH}_{4} /$ air $/ \mathrm{O}_{3}$ mixture with $\gamma_{\mathrm{O}_{3}}=5 \%$ and $P_{0}=10^{4} \mathrm{~Pa}$ to radiation at $\lambda_{I} \approx 9.7 \mu \mathrm{m}$ for $E_{0}=0.2 ; 0.5 ; 1 \mathrm{~J} / \mathrm{cm}^{2}($ curves $1,2,3$, respectively) and $\tau_{p}=10^{-5} \mathrm{~s}$ in the two cases - (1) the entire energy absorbed by ozone is consumed in heating the mixture (dotted curves) and (2) the nonequilibrium excitation of asymmetric vibrations of $\mathrm{O}_{3}$ molecule by laser photons (solid curves). Dashed curve corresponds to the dependence of $\tau_{\text {ind }}\left(T_{0}\right)$ for $E_{0}=0$.

\section{Concluding Remarks}

The excitation of asymmetric vibrations of $\mathrm{O}_{3}$ molecules which are admixed in a small amount to $\mathrm{H}_{2}$ /air or to $\mathrm{C}_{n} \mathrm{H}_{m}$ /air $\left(\mathrm{C}_{n} \mathrm{H}_{m}=\mathrm{CH}_{4}, \mathrm{C}_{2} \mathrm{H}_{2}\right)$ mixtures by means of $\mathrm{CO}_{2}$-laser radiation at $\sim 9.7 \mu \mathrm{m}$ wavelength leads to an enhancement of ignition/combustion development. Such a method of radiation energy supply to the reactive systems makes it possible to reduce considerably the induction time for both $\mathrm{H}_{2}$ /air and $\mathrm{CH}_{4}\left(\mathrm{C}_{2} \mathrm{H}_{2}\right)$ /air mixtures and to decrease the ignition temperature at low radiation energy deposited to the gas $\left(E_{a}=10^{-3}-5 \cdot 10^{-3} \mathrm{~J} / \mathrm{cm}^{3}\right)$. These effects are caused primarily by the intensification of chain reactions due to the formation of a significant amount of $\mathrm{O}$ atoms in the mixture exposed to the resonance laser radiation upon accelerated dissociation of vibrationally activated $\mathrm{O}_{3}$ molecules and due to the heating of the mixture upon the faster decomposition of excited ozone molecules. The efficiency of the approach based on the excitation of vibrations of reactive molecules to enhance the ignition/combustion is many times higher than that based on the local heating of the medium by laser radiation, especially for mixtures in which the time of reactive radical and atom formation does not exceed significantly the relaxation time of vibrations of excited molecules. The decrease in ignition temperature due to the exposure of the combustible mixtures by $\mathrm{CO}_{2}$-laser radiation at $\sim 9.71 \mu \mathrm{m}$ wavelength allows one to increase significantly (by 30\%) the chemical energy released in heating during combustion, as compared to the conventional approach of the thermal ignition. These effects are not associated with the heating of 
the gas due to absorption of laser radiation but are caused by the generation of highly reactive $\mathrm{O}$ atoms due to dissociation of vibrationally excited $\mathrm{O}_{3}$ molecules.

\section{Acknowledgments}

This work was supported by the Russian Foundation for Basic Research under Projects Nos. 05-0216419 and 05-01-00355 and by INTAS under Grant No. 03-51-4736.

\section{References}

1. G. G. Light, J. Chem. Phys., 68, 2831-2843 (1978).

2. A. Lifshitz and H. Teitelbaum, Chem. Phys., 219, 243 (1977).

3. A. M. Wodtke, Phys. Chem. Earth C, 26, 467-471 (2001).

4. N. Balakrishnan, Geophys. Res. Lett., 31, L04106 (2004).

5. B. Raffel, J. Warnatz, and J. Wolfrum, J. Appl. Phys. B, 37, 189-195 (1985).

6. D. Lucas, D. Dunn-Rankin, K. Hom, and N. J. Brown, Combust. Flame, 69, 171-184 (1987).

7. P. D. Ronney, Opt. Engineering, 33, 510-521 (1994).

8. M. A. Tanoff, M. D. Smooke, R. E. Teets, and J. A. Sell, Combust. Flame, 103, 253-280 (1995).

9. J. X. Ma, D. R. Alexander, and D. E. Poulain, Combust. Flame, 112, 492-506 (1998).

10. A. M. Starik and N. S. Titova, Proc. SPIE, 4760, 609-620 (2002).

11. A. M. Starik and N. S. Titova, Tekh. Fiz., 49, 1116-1125 (2004).

12. J. S. Margolis, J. Quant. Spectrosc. Radiat. Transfer., 29, 539-542 (1983).

13. V. V. Lunin, M. P. Popovich, and N. S. Tkachenko, Physical Chemistry of Ozone [in Russian], M. V. Lomonosov Moscow State University (1998).

14. K. M. Leung and R. P. Lindstedt, Combust. Flame, 102, 129-160 (1995).

15. J. M. Simmie, Prog. Energy Combust. Sci., 29, 599 (2003).

16. N. G. Dautov and A. M. Starik, Kinet. Catal., 38, 185-208 (1997).

17. Y. Hidaka, K. Hattori, T. Okuno, et al., Combust. Flame, 107, 401-417 (1996).

18. A. Laskin and H. Wang, Chem. Phys. Lett., 303, 43-49 (1999).

19. F. Menard-Bonrein, C. Boursier, L. Doyennette, and J. Menard, J. Chem. Phys. A, 105, 11446-11454 (2001).

20. A. M. Starik and N. S. Titova, Tekh. Fiz., 46, 929-940 (2001).

21. G. G. Chernyi, S. A. Losev, S. O. Macheret, and V. P. Potapkin, Prog. Astronaut. Aeronaut., 196 (2002).

22. V. A. Sal'nikov and A. M. Starik, High Temper., 33, 121 (1995).

23. V. I. Grabovskii and A. M. Starik, Quantum Electron., 24, 340-345 (1994).

24. A. M. Starik and N. S. Titova, Kinet. Catal., 41, 589-596 (2000).

25. B. I. Loukhovitskii, A. M. Starik, and N. S. Titova, Kinet. Catal., 45, 847-853 (2004).

26. Ya. B. Zel'dovich, G. L. Barenblatt, V. B. Librovich, and G. M. Makhviladze, Mathematical Theory of Combustion and Explosion [in Russian], Nauka, Moscow (1980). 